\title{
Multiscale fabrication of biomimetic scaffolds for tympanic membrane tissue engineering
}

Citation for published version (APA):

Mota, C., Danti, S., D'Alessandro, D., Trombi, L., Ricci, C., Puppi, D., Dinucci, D., Milazzo, M., Stefanini, C., Chiellini, F., Moroni, L., \& Berrettini, S. (2015). Multiscale fabrication of biomimetic scaffolds for tympanic membrane tissue engineering. Biofabrication, 7(2), [025005]. https://doi.org/10.1088/1758$5090 / 7 / 2 / 025005$

Document status and date:

Published: 01/06/2015

DOI:

10.1088/1758-5090/7/2/025005

Document Version:

Publisher's PDF, also known as Version of record

Document license:

Taverne

Please check the document version of this publication:

- A submitted manuscript is the version of the article upon submission and before peer-review. There can be important differences between the submitted version and the official published version of record.

People interested in the research are advised to contact the author for the final version of the publication, or visit the DOI to the publisher's website.

- The final author version and the galley proof are versions of the publication after peer review.

- The final published version features the final layout of the paper including the volume, issue and page numbers.

Link to publication

\footnotetext{
General rights rights.

- You may freely distribute the URL identifying the publication in the public portal. please follow below link for the End User Agreement:

www.umlib.nl/taverne-license

Take down policy

If you believe that this document breaches copyright please contact us at:

repository@maastrichtuniversity.nl

providing details and we will investigate your claim.
}

Copyright and moral rights for the publications made accessible in the public portal are retained by the authors and/or other copyright owners and it is a condition of accessing publications that users recognise and abide by the legal requirements associated with these

- Users may download and print one copy of any publication from the public portal for the purpose of private study or research.

- You may not further distribute the material or use it for any profit-making activity or commercial gain

If the publication is distributed under the terms of Article $25 \mathrm{fa}$ of the Dutch Copyright Act, indicated by the "Taverne" license above, 
PAPER

\section{Multiscale fabrication of biomimetic scaffolds for tympanic membrane tissue engineering}

To cite this article: Carlos Mota et al 2015 Biofabrication 7025005

View the article online for updates and enhancements.

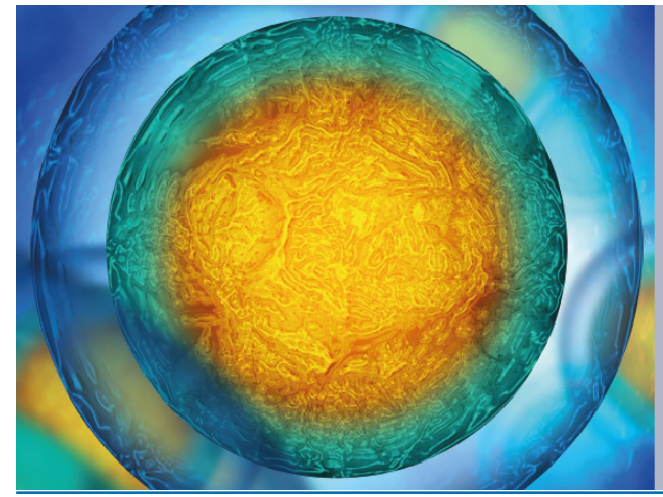

Biophysical Society $\quad$ IOP $\mid$ ebookS $^{\text {TM }}$

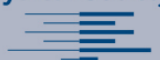

Related content

- Additive manufactured polymeric 3D scaffolds with tailored surface topography influence mesenchymal stromal cells activity

Sara C Neves, Carlos Mota, Alessia Longoni et al.

- Surface modification of electrospun fibre meshes by oxygen plasma for bone regeneration

A Nandakumar, Z Tahmasebi Birgani, D Santos et al.

- Processing large-diameter poly(L-lactic acid) microfiber mesh/mesenchymal stromal cell constructs via resin embedding: an efficient histologic method Delfo D'Alessandro, Gianni Pertici, Stefania Moscato et al.

\section{Recent citations}

- Acoustic transmitted electrospun fibrous
$\frac{\text { membranes for tympanic membrane }}{\text { regeneration }}$
Bing Wang et al
- Molecular oriain of viscoelasticity in
$\frac{\text { mineralized collagen fibrils }}{\text { Mario Milazzo et al }}$
- $\frac{\text { Necessities, opportunities, and challenges }}{\text { for tympanic membrane perforation }}$
$\frac{\text { Scaffolding-based bioengineering }}{\text { Zahid Hussain and Renjun Pei }}$




\title{
Biofabrication
}

\section{PAPER}

CrossMark

\section{Multiscale fabrication of biomimetic scaffolds for tympanic}

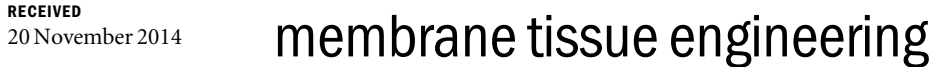

REVISED

6 March 2015

ACCEPTED FOR PUBLICATION

16 March 2015

PUBLISHED

7 May 2015

\author{
Carlos Mota ${ }^{1,2,3,4}$, Serena Danti ${ }^{1,5}$, Delfo D'Alessandro ${ }^{1}$, Luisa Trombi ${ }^{1}$, Claudio Ricci ${ }^{1}$, Dario Puppi ${ }^{3}$, \\ Dinuccio Dinucci ${ }^{3}$, Mario Milazzo ${ }^{5}$, Cesare Stefanini ${ }^{5}$, Federica Chiellini ${ }^{3}$, Lorenzo Moroni ${ }^{2,4}$ and \\ Stefano Berrettini \\ 1 Laboratory of Temporal Bone Dissection and Otologic Tissue Engineering (OtoLab), Department of Surgical, Medical, Molecular \\ Pathology and Emergency Medicine, University of Pisa, Pisa, Italy \\ 2 Institute for Biomedical Technology \& Technical Medicine (MIRA), Tissue Regeneration Department, University of Twente, Enschede, \\ The Netherlands \\ 3 Laboratory of Bioactive Polymeric Materials for Biomedical and Environmental Applications (BIOLab), Department of Chemistry and \\ Industrial Chemistry, University of Pisa, Pisa, Italy \\ 4 Institute for Technology Inspired Regenerative Medicine (MERLN), Complex Tissue Regeneration Department, Maastricht University, \\ Maastricht, The Netherlands \\ 5 Laboratory of Creative Engineering \& Design, the Biorobotics Institute, Scuola Superiore Sant'Anna, Pontedera (PI), Italy \\ E-mail: s.danti@med.unipi.it
}

Keywords: tympanic membrane, electrospinning, additive manufacturing, mesenchymal stromal cells, myringoplasty, tympanoplasty, multiscale

\begin{abstract}
The tympanic membrane (TM) is a thin tissue able to efficiently collect and transmit sound vibrations across the middle ear thanks to the particular orientation of its collagen fibers, radiate on one side and circular on the opposite side. Through the combination of advanced scaffolds and autologous cells, tissue engineering (TE) could offer valuable alternatives to autografting in major TM lesions. In this study, a multiscale approach based on electrospinning (ES) and additive manufacturing (AM) was investigated to fabricate scaffolds, based on FDA approved copolymers, resembling the anatomic features and collagen fiber arrangement of the human TM. A single scale TM scaffold was manufactured using a custom-made collector designed to confer a radial macro-arrangement to poly (lactic-co-glycolic acid) electrospun fibers during their deposition. Dual and triple scale scaffolds were fabricated combining conventional ES with AM to produce poly(ethylene oxide terephthalate)/poly (butylene terephthalate) block copolymer scaffolds with anatomic-like architecture. The processing parameters were optimized for each manufacturing method and copolymer. TM scaffolds were cultured in vitro with human mesenchymal stromal cells, which were viable, metabolically active and organized following the anisotropic character of the scaffolds. The highest viability, cell density and protein content were detected in dual and triple scale scaffolds. Our findings showed that these biomimetic micro-patterned substrates enabled cell disposal along architectural directions, thus appearing as promising substrates for developing functional TM replacements via TE.
\end{abstract}

\section{Introduction}

The tympanic membrane (TM), or eardrum, is a thin, flexible and tough membrane separating the external from the middle ear compartment and devoted to the transmission of the sound waves to the ear ossicles. Human TM thickness has been measured by several researchers and reported to be lower than $100 \mu \mathrm{m}$ [1]. Histologically, TM is composed of three layers, thus resulting in a tri-laminar tissue. The mid layer is connective tissue proper, while the outer layers are epidermal or mucosal epithelia. The largest area of the eardrum is known as pars tensa and is made up of collagen fibers responsible for the deformation resistance of TM due to specific spatial orientations: outer radial, inner circular, with an adjunct parabolic fiber beam with fulcrum in the umbo (figures 1(a)(e)) [2]. Such a complex collagenous network reflects and is essential for the correct vibratory function of $\mathrm{TM}[3]$. 


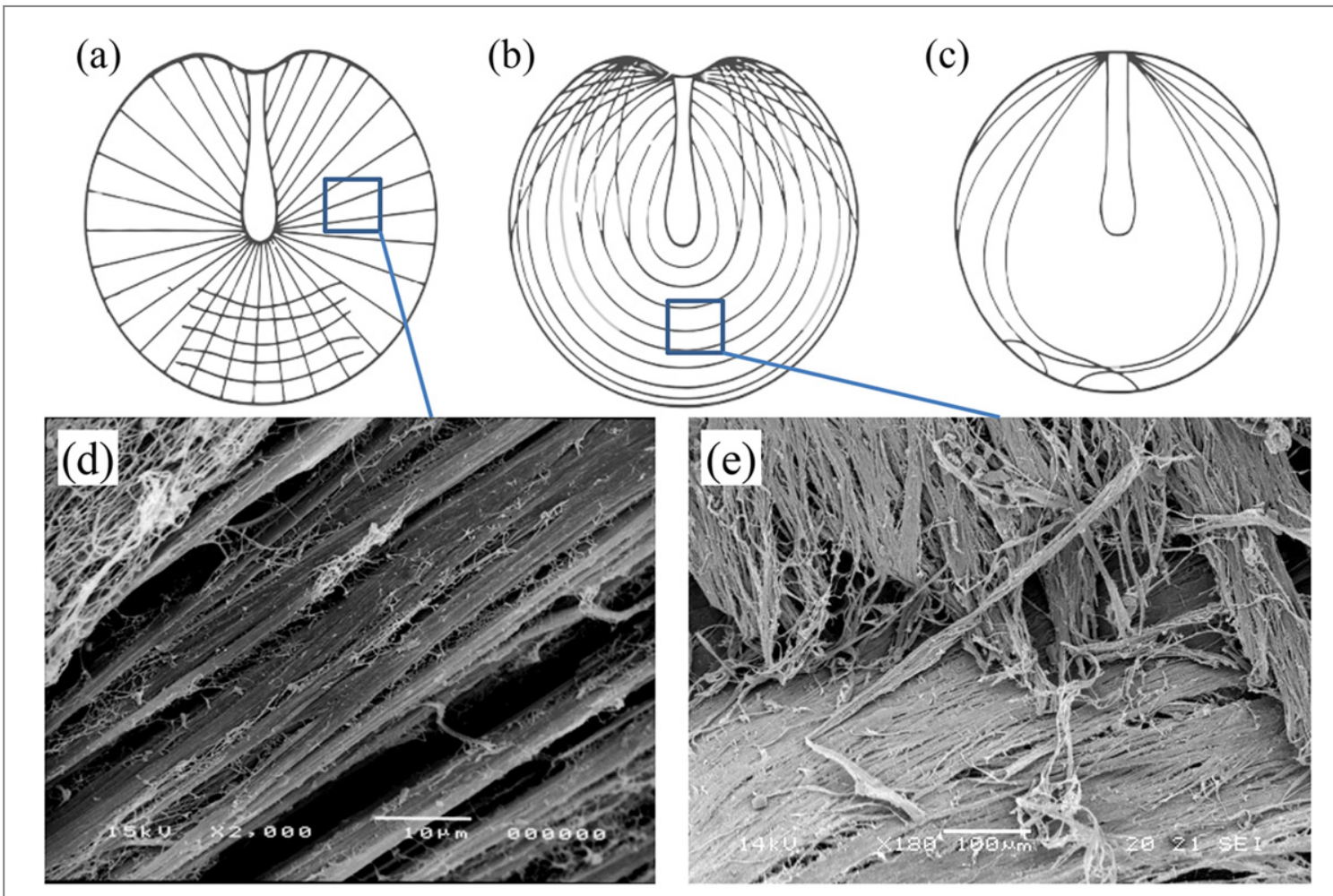

Figure 1. Schematic representation of the different collagen fiber layers forming human TM: (a) radial fibers; (b) circular fibers; and (c) parabolic fibers. SEM micrographs of the human TM, showing collagen fibers: (d) radial collagen fibers; and (e) detail with radial and circular collagen fibers.

The middle ear can be affected by several pathologies, including the tympanic perforations, which represent a widespread clinical problem, with onset in childhood [4]. Structural damages to TM are usually a consequence of trauma or infections (e.g., chronic otitis media) and can lead to conductive hearing loss [5]. In fact, even though most minor lesions of TM can heal spontaneously, extensive lesions are repaired via surgery. Several biomaterials have been tested for the closure of TM lesions. The first attempts to seal TM perforations were performed in the 17 th century using pig bladder [6]. Since then, a number of decellularized xenografts have been investigated. However, only some in vivo studies on animal models have been reported so far [7]. To date, autologous tissues (e.g., perichondrium, cartilage) are chiefly implanted, since the autologous temporalis fascia is considered the gold standard material in TM reconstruction [8]. Homografts have also been proposed $[9,10]$, although the risk of disease transmission has limited the use of this approach. Among the tissue-grafts, cartilage has shown rigidity characteristics able to favor sound conduction [10, 11]. Despite the good results generally obtained when autologous materials are applied, patients undergoing revision surgery can present insufficient availability of tissue for repeated autografting [12]. New strategies involving the principles of tissue engineering (TE) have been recently explored to attempt TM regeneration $[13,14]$. In these studies, as reviewed by Teh et al and Hong et al, the application of scaffolds is aimed at accelerating TM healing and usually relies on the following approaches: (i) implanting acellular scaffolds to permit in vivo cell migration $[15,16]$, and (ii) implanting keratinocyte/ silk-based constructs as in vitro pre-cultured cell/scaffold constructs $[17,18]$. Other non-surgical approaches for TM healing exploit the topical application of growth factors such as platelet-derived growth factor, as proposed by Roosli et al [19], and basic fibroblast growth factor combined with gelatin sponges [15], which have shown promising results. However, despite the large number of materials, approaches and surgical techniques tested so far, the optimal solution for TM closure or replacement in critical lesions is still lacking.

In relation to the peculiar anatomic and histologic features of the human TM, some scaffolding techniques show theoretical advantages that can be exploited for whole TM regeneration via TE. Since the two epithelia have shown to spontaneously migrate in vivo, the main requirement of a TM scaffold is to act as a support for the neo-formation of the collagenous network, which is the key structural element of TM biomechanics [1-3]. Advanced scaffolds with biomimetic cues, such as the emulation of anatomic and histologic features, should be developed to achieve optimal functional results.

Electrospinning (ES) is one of the most popular and exploited techniques for producing thin scaffolds for diverse TE applications [20-22]. Indeed, ES is 
simple, cost-effective and allows the production of polymeric ultrafine fiber structures resembling the fibrous elements of the extracellular matrix (ECM) [20]. The high surface area to volume ratio is a typical advantage of electrospun meshes, as it provides great many sites for cell adhesion [20]. The possibility of producing electrospun meshes able to induce cell alignment is one of the advantages of tuning fiber orientation [21]. Different collectors have been used to obtain tailored non-woven meshes with different fiber arrangements [22]. The flexibility of this techniques has been largely explored. As an example, coaxial ES has been proposed for the deposition of living cells encapsulated within biocompatible beaded fibers, so as to produce biohybrid microthreads in the form of spatially-oriented preformed cell/mesh composites $[23,24]$. Cell ES represents a versatile and complete platform for the generation of tissue engineered constructs that will possibly find clinical applications in the close future [24].

Additive manufacturing (AM) techniques allow customized forms to be produced via computer-assisted control also used for the fabrication of scaffolds in a number of TE applications [25]. In addition, the combination of AM and ES has interestingly been proposed to obtain the manufacturing of multiscale scaffolds with improved mechanical and biological properties [26].

Ideally, the replication of the TM collagen fibers could only be achieved producing different layers of electrospun fibers, so as to resemble the different orientations of the natural ECM (i.e., radial on one side and circular on the other side). Despite the several advantages shown by ES, the necessity of minimal mechanical stability for handling and application on the affected site is a key requirement for a tissue-engineered TM [13].

The aim of this study was the production of advanced scaffolds using multiscale strategies to obtain biomimetic substrates for TM TE: (i) the first approach (namely, 'single scale') exploited an advanced ES technique, able to spin ultrafine fibers collected with radial orientation via a custom-made collector, and (ii) the second approach (namely, 'dual and triple scale') exploited conventional ES in combination with $\mathrm{AM}$ techniques to produce multiscale scaffolds, in which radial and circular microfiber patterns were applied to an electrospun fiber mesh. Single and dual/triple scale approaches were tested using two different copolymers, FDA-approved and widely used in biomedical applications: (i) poly(lactic-co-glycolic) acid (PLGA), and (ii) a random block copolymer of poly(ethylene oxide terephthalate) and poly(butylene terephthalate) (PEOT/PBT), respectively. The manufacturing parameters were optimized for each fabrication technique. The morphologic features of the scaffolds were analyzed in relation to those of human TMs via scanning electron microscopy. Finally, a preliminary biological study was conducted by culturing human mesenchymal stromal cells (MSCs) on TM scaffolds to generate cellular constructs in vitro. Cell adhesion, viability, protein production and scaffold colonization were investigated. Biomimetic micro-patterned substrates enabling cell disposal along architectural directions could represent a valuable strategy for the regeneration of functional TM substitutes via TE.

\section{Materials and methods}

\subsection{Materials}

PLGA (75:25 w/w lactide/glycolide, $\quad \mathrm{Mw}=$ $120000 \mathrm{~g} \mathrm{~mol}^{-1}$ ) was purchased from Lakeshore Biomaterials Inc. (Birmingham, USA). Polyactive ${ }^{\circledR}$ was provided by PolyVation BV (Groningen, The Netherlands). This commercial random block copolymer is composed of PEOT and PBT and is also named PEOT/ PBT (300PEOT55PBT45). The commercial nomenclature $a \mathrm{PEOT} b \mathrm{PBT} c$ represents: $(a)$ the molecular weight $\left(\mathrm{Mw}, \mathrm{g} \mathrm{mol}^{-1}\right)$ of the poly(ethylene glycol), (b) and $(c)$ the weight ratios of PEOT and PBT, respectively. Chloroform was supplied by Merck KGaA (Darmstadt, Germany), hexafluorisopropanol (HFIP) by Biosolve BV (Valkenswaard, The Netherlands), acetone by Sigma Aldrich (Milan, Italy), absolute ethanol by Bio-Optica (Milan, Italy). Low-glucose (1000 mg L ${ }^{-1}$ ) Dulbecco's Modified Eagles Media (DMEM), L-glutamine, and penicillin-streptomycin (Pen-Strep), trypsin, phosphate buffered saline (PBS), gelatin (type B, 75 Bloom, from bovine skin), Triton $\mathrm{X}-100$, trypan blue, methylene blue solution and bovine serum albumin (BSA) were provided by Sigma-Aldrich. Heat-inactivated fetal bovine serum (FBS), PicoGreen kit (Quant-iT ${ }^{\mathrm{TM}}$ ), 4'-6'-diamidino2-phenylindole (DAPI), Sytox Green, phalloidinAlexa633, phalloidin-Alexa488 were purchased from Invitrogen (Carlsbad, CA, USA). Lymphoprep was supplied by Axis-Shield, Norway. Calcium chloride for human use was purchased from Bioindustria Farmaceutici (Rome, Italy). AlamarBlue ${ }^{\circledast}$ was provided by Serotec Ltd (Kidlington, UK). The bicinchoninic acid (BCA) kit was purchased from Pierce Biotechnology (Rockford, IL, USA). DPX mounting agent was bought from Fluka (Buchs, Switzerland). All the products were used as received, if not otherwise specified in the methods section.

\subsection{Ethical statement}

The human TMs analyzed in this study were collected from certified formalin-fixed cadaveric temporal bones, purchased from International Biologicals Inc. (Detroit, MI, USA) for research use only.

The human MSCs used for the in vitro studies were isolated in our laboratories from bone marrow samples obtained during hip arthroplasty procedures. The patients signed a written informed consent before the intervention. After collection, the bone marrow specimens were treated anonymously and in conformity to 
the principles expressed by the Declaration of Helsinki. The use of bone marrow for pilot research studies in regenerative medicine was approved by the Ethics Committee of Pisa hospital.

\subsection{Microanatomic analysis of human TMs}

Human TMs $(n=2)$ were drawn from two formalinfixed temporal bones via microdissection under surgical microscopy (OPMI microscope, Carl Zeiss, Oberkochen, Germany). Specimens of pars tensa dissected from human TMs were dehydrated in a graded series of ethanol aqueous solutions up to anhydrous ethanol using the critical point method (Balzers CPD030; Oerlikon Balzers, Liechtenstein), mounted on aluminum stubs, sputter-coated with gold (Emitech K550; Quorum Technologies Ltd, West Sussex, UK), and observed by scanning electron microscopy (SEM; JSM-5200, JEOL Ltd, Tokyo, Japan) in order to assess their microanatomic details and dimensions (figures $1(\mathrm{a})$ and (b)).

\subsection{Manufacturing of TM scaffolds}

The scaffolds were designed so as to be produced with a size comparable to that of a human TM (including the eardrum margin), namely, diameter $=15 \mathrm{~mm}$ and thickness $\leqslant 100 \mu \mathrm{m}$. To replicate the main architectural directions shown by the natural collagen fibers in the TM (figures 1(a) and (b)), two different approaches for scaffold manufacturing were investigated: (i) a first approach, using a custom-made collector in combination with an ES apparatus to produce single scale scaffolds with intrinsic radial patterns; and (ii) a second approach, combining ES with $\mathrm{AM}$, to manufacture dual and triple scale scaffolds with superimposed radial and/or circular patterns. Specifically, an AM technique named threedimensional fiber deposition (3DF) was used.

\subsubsection{Preparation of copolymer solutions}

PLGA copolymer was dissolved in acetone at a concentration of $20 \% \mathrm{w} / \mathrm{v}$ under gentle stirring for $2 \mathrm{~h}$ at room temperature to obtain a homogeneous solution, as described in previous studies [26, 27]. PEOT/ PBT copolymer solution was prepared with a concentration of $20 \% \mathrm{w} / \mathrm{v}$ in a solvent mixture of chloroform and HFIP (90/10 v/v), as previously reported by Moroni et al [28]. The solution was kept under gentle stirring overnight prior to usage.

\subsubsection{Fabrication of single scale patterned scaffolds}

For the production of the patterned PLGA scaffolds, an ES apparatus with a screen-to-screen configuration was used to obtain a focused fiber collection area (figures 2(a) and (b)) [26, 27, 29]. Meshes resembling the biomimetic disposal of the natural collagen fibers of the TM, hereinafter referred to as single scale TM scaffold (figure 2(c)), required the development of a customized collector designed to allow the arrangement of the electrospun fibers with macroscaled radial orientation (figure 2(b)). The collector, composed of a resin insulator support base and a conductive brass array consisting of an external ring and 24 radii, was attached to the center of the aluminum counter-electrode and the brass array was connected to the plate (figure 2(b)). A $20 \mathrm{~mm}$ diameter coverslip was placed on top of the collector to gather the fibers. Two high voltage power supplies with opposite polarities (SL60PN300, Spellman High Voltage, West Sussex, UK) were employed. A constant potential difference $(V)$ of $30 \mathrm{kV}$ was used by applying a positive charge of $15 \mathrm{kV}$ to needle and auxiliary electrode, and a negative charge of $-15 \mathrm{kV}$ to counterelectrode and collector (figure 2(a)). The working distances were kept constant in all the experiments, specifically, the electrode plate to plate distance $\left(d_{1}\right)$ was $18 \mathrm{~cm}$, the needle tip to counter-electrode distance $\left(d_{2}\right)$ was $15 \mathrm{~cm}$ and the needle tip to patterned collector distance $\left(d_{3}\right)$ was $14 \mathrm{~cm}$. A syringe pump (BSP-99M, Braintree Scientific Inc., Braintree, MA, USA) was used to control the solution feed rate $\left(F=1 \mathrm{ml} \mathrm{h}^{-1}\right)$. The PLGA solution was loaded inside a $5 \mathrm{ml}$ syringe equipped with a 21-gauge stainless steel blunt needle.

The collection time ranged in $1-5 \mathrm{~min}$. The optimized processing parameters are reported in table 1 . All the fabricated TM meshes were dried under a fume hood and vacuum was applied for $24 \mathrm{~h}$ to strip out the solvent.

\subsubsection{Fabrication of dual and triple scale patterned scaffolds}

Manufacturing of the dual and triple scale PEOT/PBT scaffolds involved several steps, as shown in figure 3. A 3DF technique (3D-Bioplotter ${ }^{\mathrm{TM}}$, EnvisionTEC $\mathrm{GmbH}$, Gladbeck, Germany) was used to produce micro-patterned grids (figures $3(\mathrm{a}),(\mathrm{c})$ and $(\mathrm{d})$ ) to be combined with an electrospun mesh (figures 3(b), (c), (e)-(g)). The 3DF AM equipment uses the principle of fused deposition modeling assisted by nitrogen $\left(\mathrm{N}_{2}\right)$ gas pressure to promote the extrusion of a molten copolymer. The parameters that influence the production of the 3D scaffolds are: temperature, $\mathrm{N}_{2}$ pressure, deposition velocity and extrusion nozzle diameter. A detailed description of the system was previously reported $[28,30]$. Briefly, the system is composed of a stainless steel syringe in which the PEOT/PBT copolymer was loaded and heated at $205^{\circ} \mathrm{C}$. After the copolymer was completely melted, a pressure of 5.5 bar of $\mathrm{N}_{2}$ was applied. The extrusion of the copolymer was controlled by an electrovalve. For the fabrication of the TM microfiber pattern, a nozzle with a diameter of $200 \mu \mathrm{m}$ was used (Gauge 27). The deposition velocity was $15 \mathrm{~mm} \mathrm{~min}^{-1}$. Two patterned grids (radial and circular) that mimic the TM collagen fiber alignment were designed using Rhinoceros ${ }^{\otimes}$ software (McNeel, Seattle, WA, USA), exported to the 3DF equipment and fabricated as layers to be coated with 


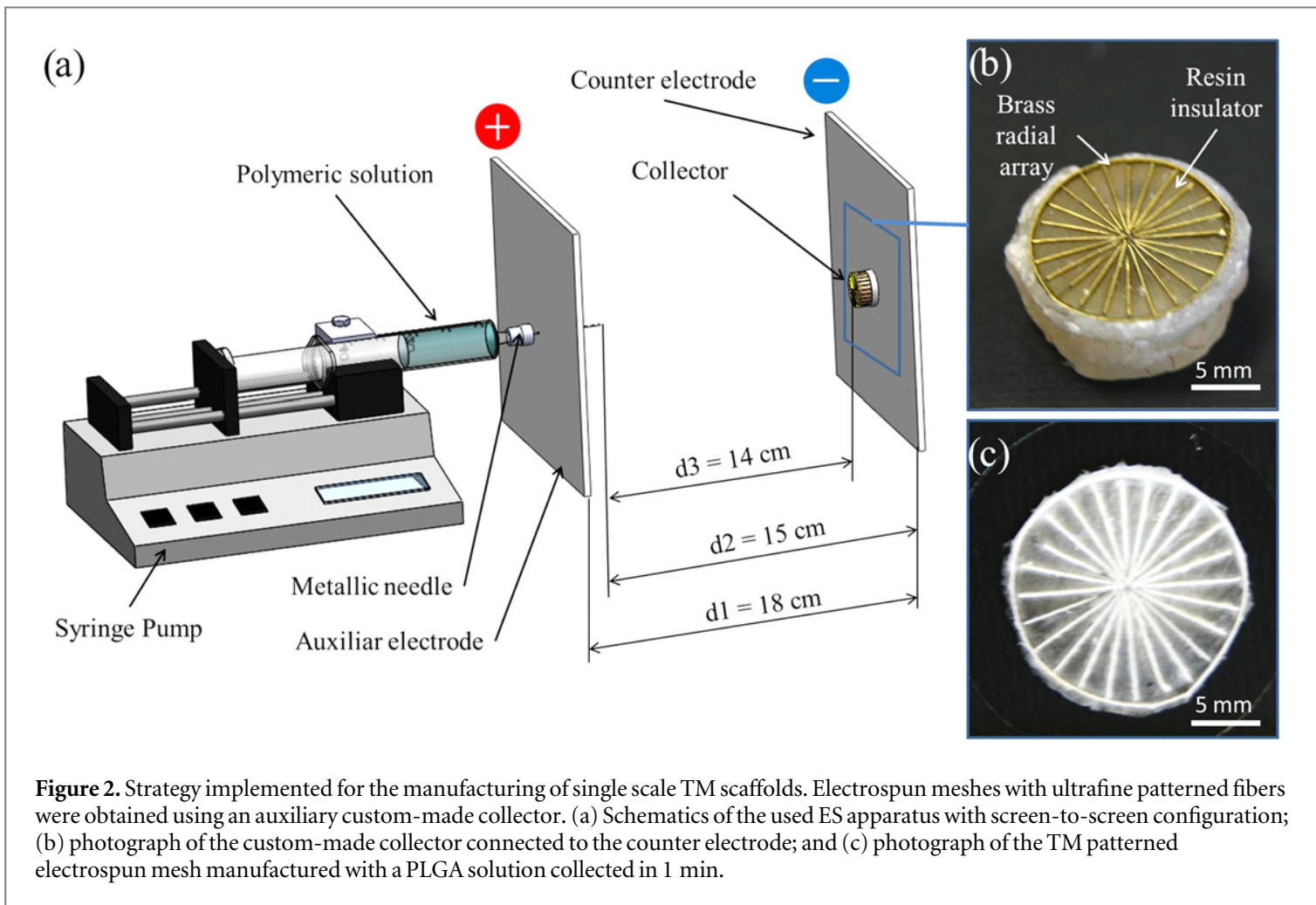

Table 1. Processing parameters used for the manufacturing of the electrospun meshes.

\begin{tabular}{lclllc}
\hline Copolymer & Concentration $(\% \mathrm{w} / \mathrm{v})$ & Solvents & Voltage $(\mathrm{kV})$ & $d_{1} / d_{2} / d_{3}(\mathrm{~cm})$ & $F\left(\mathrm{ml} \mathrm{h}^{-1}\right)$ \\
\hline PLGA & 20 & $\mathrm{C}_{3} \mathrm{H}_{6} \mathrm{O}$ & $30(-15 / 15)$ & $18 / 15 / 14$ & 1 \\
PEOT/PBT & 20 & $\mathrm{CHCl}_{3} / \mathrm{HFIP}(90 / 10)$ & 15 & $-/-/ 15$ & 5 \\
\hline
\end{tabular}

$d_{1}$ - distances between the two electrode plates;

$d_{2}$-distance between the needle tip and the counter electrode;

$d_{3}$ - distance between the needle tip and the patterned collector;

F-copolymer feed rate.

electrospun meshes (figure 3(c)). Two types of patterned scaffolds were prepared. In the first prototype, the radial and circular grid layers were manufactured as a single piece and subsequently coated with a thin electrospun mesh, finally resulting in a dual scale TM scaffold (figures $3(\mathrm{a})-(\mathrm{e})$ ). In this case, the microfiber patterns obtained via $3 \mathrm{DF}$ followed the simplified design of the collagen fibers of the human TM (figures 1(a) and (b)) [31]. As an example, this grid pattern can represent the collagen arrangement in the area opposite the umbo (figure 1(a)). In the second prototype, the electrospun mesh was placed in between the radial and the circular grid layers, fabricated as two separate pieces, thus obtaining a membrane with a diversely oriented pattern on each side. From a fabrication standpoint, such a doublefaced patterned membrane is a triple scale TM scaffold (figures 3(f) and $(\mathrm{g})$ ). An ES apparatus was used to manufacture the PEOT/PBT mesh on top and in between the microfiber layers (figure 3(b)). It comprises of a three-axis system (CNC-STEP, Geldern, Germany) that permits the positioning and movement of the spinneret during the ES process. The system also comprises of a syringe pump (KDS 100, KD Scientific, Holliston, MA, USA) controlling the copolymer solution feed rate, and a high voltage power supply (Gamma High Voltage Research Inc., Ormond Beach, FL, USA) capable of generating $0-30 \mathrm{kV}$. The spinneret was positively charged and the ground was attached to the collector covered with an aluminum foil. The microfiber patterned grids were placed on top of an aluminum foil and the spinneret was aligned with the center of the pattern prior to the generation of the mesh. The control of working conditions (i.e., temperature and humidity) inside the ES confinement chamber was assisted by an ad hoc ventilation system. During the production of PEOT/PBT electrospun meshes the temperature was set to $25^{\circ} \mathrm{C}$ and the humidity to $30 \%$. The copolymer solution was loaded inside a $5 \mathrm{ml}$ plastic syringe, placed on the syringe pump and dispensed at feed rate of $5 \mathrm{ml} \mathrm{h}^{-1}$.

The optimized processing parameters are reported in table 1 . An electric potential of $15 \mathrm{kV}$ and a distance between the spinneret and the $15 \mathrm{~cm}$ collector were used and kept constant for all experiments. Three collection times were evaluated: 30,60 and $120 \mathrm{~s}$, for the 
a) 3D Fiber Deposition (3DF)
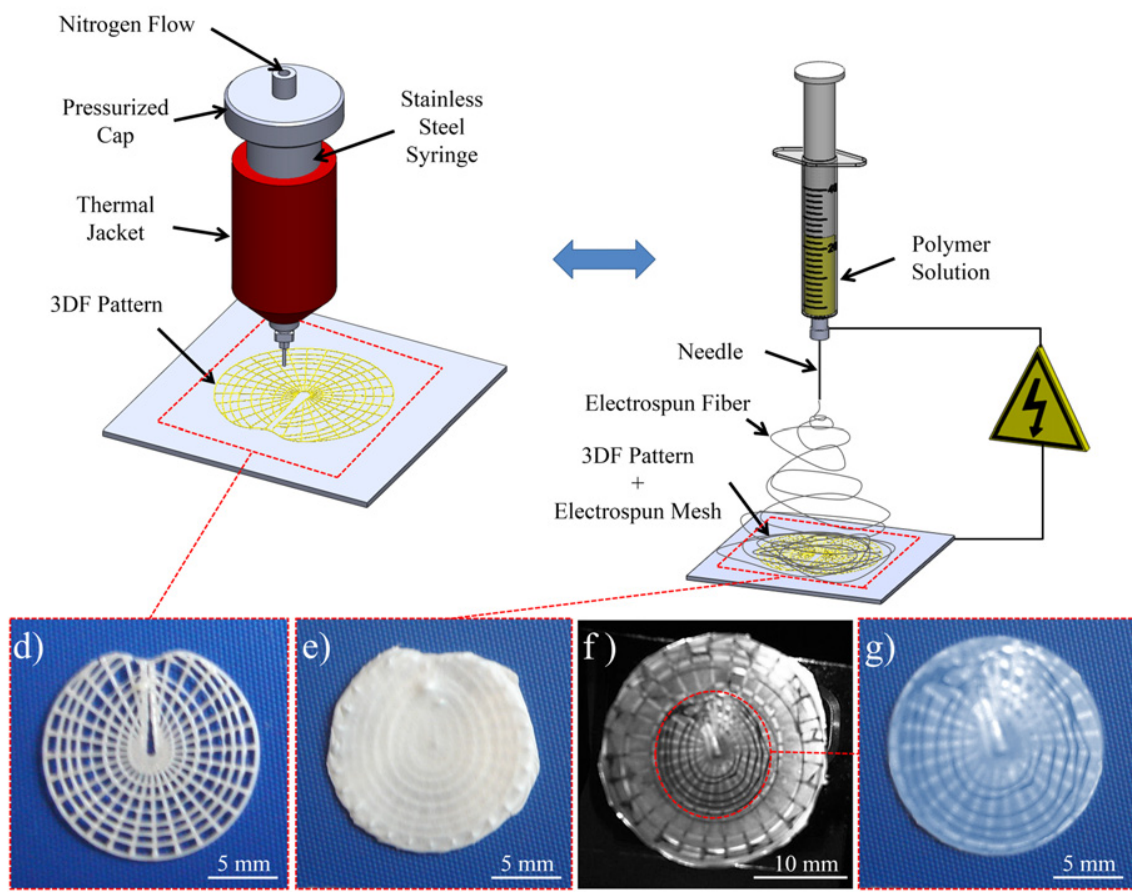

c)

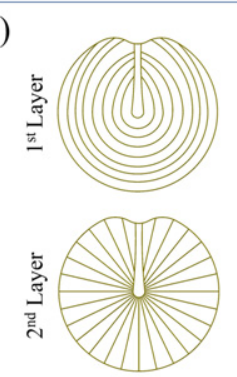

Dual scale TM scaffold ES

ES
+

3DF

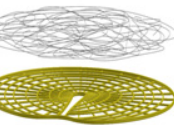

Triple scale TM scaffold

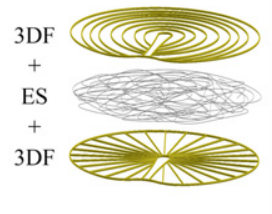

Figure 3. Strategy implemented for the production of dual and triple scale scaffolds for TM scaffolds. (a) and (b) a first step comprises the production of the AM pattern via 3D fiber deposition technique and subsequent coating of the pattern with a PEOT/PBT electrospun mesh. (c) Simplified patterns designed with Rhinoceros ${ }^{\circledast}$ with circular concentric microfibers (1st layer) and radial microfibers (2nd layer) and schematic drawings of dual and triple TM scaffolds with exploded view. (d) and (e) photographs of onepiece grid layer before and after coating with the electrospun membrane (dual scale TM scaffold). (f) and (g) photographs of a triple scale TM scaffold, as produced on a large frame and the region of interest being carved out, showing circular and radial layers on different membrane sides.

mesh thickness optimization. After fabrication, PEOT/PBT scaffolds were treated with argon plasma to improve cell adhesion, as previously described [32]. Briefly, the scaffolds were placed inside the radio-frequency glow-discharge chamber (Harrick Plasma Inc., Ithaca, NY, USA). After the pre-vacuum was reached, the chamber was flushed with argon gas for $30 \mathrm{~min}$. A vacuum ranging in $0.1-0.2 \mathrm{mbar}$ was applied and the radio-frequency coil was set to $740 \mathrm{~V} \mathrm{dc}, 40 \mathrm{~mA}$ dc, 29.6 W.

\subsubsection{Morphologic analysis of TM scaffolds}

Diameters of electrospun and 3DF fibers, thickness of single-scale meshes and TM scaffold morphology were analyzed via SEM. The scaffolds were sputter-coated with gold (Emitech K550) for 4 min prior to observation. SEM micrographs were captured at different magnifications of the diverse regions of interest. Single scale TM scaffolds were imaged with a Zeiss EVO MA10, dual scale TM scaffolds with a Phillips XL30 ESEM-FEG and triple scale TM scaffolds with a JSM5200 , at an accelerating voltage of $10-15 \mathrm{kV}$. Measurements of electrospun fiber diameters for single, dual and triple scale TM scaffolds were performed over at least 100 fibers per sample, acquired from randomly selected fields. The pattern height of dual and triple scale scaffolds (i.e., 3DF fiber diameters) was similarly measured. Mesh thickness of single scale scaffolds was evaluated on inclined samples with respect to the beam. Eleven measurements for 1 and 2 min collected meshes were carried out over seven regions of interest, rescaling the results by the cosecant of the sloping angle $\left(70^{\circ}\right)$.

Pattern heights in single scale TM scaffolds were investigated via profilometry (Surfcom 130a, Carl Zeiss Industrielle Messtechnik GmbH, Oberkochen, Germany), using the underlying coverslip as a baseline. For each scaffold type, obtained with 1 and $2 \mathrm{~min}$ ES times, three measurements were carried out assaying five regions of interest containing the outer and inner surfaces. Mesh thickness in dual and triple scale TM scaffolds was measured by an electronic micrometer (Mitutoyo Corp., Tokyo, Japan), assaying five different regions within each mesh.

\subsubsection{Pore characterization in TM scaffolds}

Due to the diverse thickness of the TM scaffolds, leading to different structural properties, pore size was measured with two different techniques. Pore size and distribution of the electrospun mesh used in both dual and triple scale scaffolds $(n=2)$ was investigated via mercury intrusion porosimetry (MIP), using an $\mathrm{Hg}$ intrusion porosimeter (Pascal 140; Carlo Erba, Pomezia, Italy) equipped with an automatic recording of 
intruded $\mathrm{Hg}$ volume. The distribution of pore volumes was obtained from the derivative curve of the cumulative intruded volume, as a function of pore diameter, applying the Washburn equation

$$
d=10 \cdot 4 \gamma \cos \frac{\theta}{P}
$$

This equation states that the diameter $d(\mu \mathrm{m})$ of the Hg-filled pores (i.e., open pores), assumed to be cylinders, is inversely proportional to the intrusion pressure $P\left(\mathrm{~kg} \mathrm{~cm}^{-2}\right)$, under the condition that the $\mathrm{Hg}$ surface tension $\gamma$ and the contact angle $\theta$ between $\mathrm{Hg}$ and the material are constant.

A different technique had to be applied to evaluate the pore characteristics of single scale TM scaffolds, owing to their fragile structure that prevented MIP to be used. Size and distribution of the mesh pores were evaluated via image analysis $(n=3)$, assuming these scaffolds to be bi-dimensional. Briefly, exploiting the scaffold autofluorescence in the green channel, three representative images were captured with an inverted microscope equipped for fluorescence analysis (Nikon Eclipse TE2000) at 60× magnification and $40 \mathrm{~s}$ exposure. The micrographs representing the fibers in green and the void in black colors were analyzed with ImageJ software (version 1.48; http://imagej.nih.gov). In order to estimate the negative spaces, a threshold tool was applied. The numerical values of the selection parameters were set to give the best visual representation retracing the negative spaces between the reticulum of the fibers, by comparison to the original images. Void interspaces, 60 for each micrograph, were manually selected and their areas were measured by the software. Thereafter, the equivalent diameters were calculated assuming the pore sections to be circles (i.e., the pores to be cylinders). Finally, the data were converted from pixels to microns using an automatic scale bar for calibration. Pore volumes were calculated multiplying their sections by the mesh thickness, as measured in 2.4.4.

For all the TM scaffolds, the relative volumes of the pores were assigned to pore size classes and reported as relative volume percentages.

\subsection{Biologic evaluation of TM scaffolds}

\subsubsection{Isolation and expansion of human MSCs}

Human MSCs were obtained from bone marrow aspirates of patients admitted to our hospital for orthopedic surgery. The MSC cultures were established as reported in our previous studies, in which they were extensively characterized, showing selfrenewal and multilineage differentiation potential [33]. Briefly, the aspirate was diluted 1:3 in sterile saline and layered on Lymphoprep as a density gradient. After centrifugation at $900 \mathrm{~g}$ for $25 \mathrm{~min}$, the mononuclear cell (MNC) layer was removed from the interface and suspended in regular culture medium (CM), containing low-glucose D-MEM, $2 \mathrm{mM} \mathrm{L-}$ glutamine, $100 \mathrm{IU} \mathrm{mL}^{-1}$ penicillin, $100 \mathrm{mg} \mathrm{mL}^{-1}$ streptomycin and 10\% (v\%) heat-inactivated FBS. After further centrifuging, the MNCs suspended in CM were counted with a hemocytometer using trypan blue to check their viability, and finally plated at $0.2 \times 10^{5}$ viable cells per $\mathrm{cm}^{2}$ in tissue culture polystyrene flasks. After $24 \mathrm{~h}$, non-adherent cells were removed from the cultures through washing with sterile saline and fresh CM was added to the adherent cells. When the cultures reached about 70-80\% confluence, the adherent cells (i.e., the purified MSCs) were detached using $0.25 \%$ trypsin, replated at a cell density of $10^{3}$ cells $\mathrm{cm}^{-2}$ and expanded in regular CM. Cell cultures were carried out in incubator under standard conditions (namely, $37^{\circ} \mathrm{C}, 95 \%$ relative humidity, and 5\% $\mathrm{CO}_{2} / 95 \%$ air environment) until passage-1 MSCs reached 70\% confluence.

\subsubsection{Culture of MSC/TM scaffold constructs}

The interactions of human MSCs with TM scaffolds were evaluated. The scaffolds were sterilized by overnight soaking in absolute ethanol applying ultraviolet irradiation for $1 \mathrm{~h}$. To prevent crumpling, the outer borders of single scale scaffolds were sealed on sterile coverglasses by means of sterile fibrin glue, obtained using human plasma and calcium chloride as previously reported [33]. After gentle washing with sterile saline, all the scaffold surfaces to be seeded were coated with $2 \%$ gelatin solution in double-distilled water (w/ $\mathrm{v}$, sterile filtered). Excess gelatin solution was removed from the scaffolds before cell seeding. Human MSCs were detached with trypsin, counted under $0.2 \%$ trypan blue staining for viability evaluation, suspended in $2 \%$ gelatin solution and seeded on the scaffolds at a density of 200000 viable cells per patterned side of the scaffold, thus resulting in about $1300 \mathrm{cell} \mathrm{mm}^{-2}$ of nominal scaffold area. After seeding, MSC/scaffold constructs were placed in the incubator for $1 \mathrm{~h}$ to favor cell adhesion and finally covered with CM, at $6 \mathrm{ml}$ per sample. Triple scale scaffolds were seeded with a twostep procedure: $24 \mathrm{~h}$ after the radial side had been seeded, CM was removed, the scaffolds were flipped and seeded on the circular side following the same procedure described above. To preserve the viability of the MSCs previously seeded on the radial side during the time necessary for the newly seeded MSCs to adhere onto the circular side, $200 \mu \mathrm{l}$ of CM were left on the bottom of the plate, thus ensuring the flipped side of the scaffold to be completely wet. Cell/scaffold constructs were cultured under standard culture conditions for 8 days inside 6-well plates, replacing $\mathrm{CM}$ every 3 days. Construct viability was monitored during culture time using the alamarBlue ${ }^{\circledR}$ assay. At the endpoint, samples were processed for qualitative (SEM, methylene blue staining and confocal laser scanning microscopy (CLSM)) and quantitative (double-stranded (ds)-DNA and total protein content) analyses. 


\subsubsection{Viability of MSC/scaffold constructs}

Construct viability, measured as metabolic activity, was monitored along the culture time using the alamarBlue $^{\circledast}$ assay. Data were acquired according to manufacturer instructions and were expressed as percentage of reduced alamarBlue ${ }^{\circledast}\left(\% \mathrm{AB}_{\text {red }}\right)$. Briefly, samples $(n=3)$ and blank controls $(n=3)$ were incubated for $3 \mathrm{~h}$ at $37^{\circ} \mathrm{C}$ with the alamarBlue ${ }^{\circledR}$ dye diluted in $\mathrm{CM}$ according to the manufacturer's recommendations. Viability tests were performed every 2, 5 and 8 days after seeding. At each time-point, $100 \mu \mathrm{l}$ of supernatant from sample(s) or control(c) was loaded in 96-well plates; excess supernatant was removed from the cultures and replaced with fresh CM. The absorbance $(\lambda)$ of supernatants was measured with a spectrophotometer (Victor 3; PerkinElmer, Waltham, MA, USA) under a double wavelength reading $(570$ and $600 \mathrm{~nm})$. Finally, $\% \mathrm{AB}_{\text {red }}$ was calculated correlating the absorbance values and the molar extinction coefficients of the dye at the selected wavelengths, following the protocol provided by the manufacturer. The equation applied is shown below:

$$
\% A B_{\text {red }}=\frac{117216 \lambda_{s 570}-80586 \lambda_{s 600}}{155677 \lambda_{c 600}-14652 \lambda_{c 570}} \cdot 100 \%
$$

\subsubsection{Cellularity of MSC/scaffold constructs}

At the endpoint, the ds-DNA content in MSC/scaffold constructs was evaluated with the PicoGreen assay. The PicoGreen dye binds to ds-DNA and the resulting fluorescence intensity is directly proportional to the concentration of ds-DNA in solution [34]. To obtain ds-DNA solutions from MSC/scaffold constructs, the samples underwent cell lysis. On day 8, the CM was removed from the constructs and replaced with double-distilled sterile water, at $2 \mathrm{ml}$ per sample. The specimens $(n=3)$ were thus frozen at $-80^{\circ} \mathrm{C}$. Cell lysates were obtained following sample defrosting at $37^{\circ} \mathrm{C}$ in an ultrasonic bath (Falc, Progen Scientific, London, UK) at a frequency of $47 \mathrm{kHz}$ for $20 \mathrm{~min}$, which allowed the ds-DNA to enter the water solution. Standard solutions of DNA in double-distilled water at concentrations ranging in $0-6 \mu \mathrm{g} \mathrm{ml}^{-1}$ were prepared and $50 \mu \mathrm{l}$ of standard or sample was loaded in a 96-well black microplate. Working buffer and PicoGreen dye solutions were prepared according to the manufacturer's instructions and added at 100 and $150 \mu \mathrm{l}$ per well, respectively. After a $10 \mathrm{~min}$ incubation in the dark at room temperature, the fluorescence intensity of the samples was measured on a plate reader (Victor3), using an excitation wavelength of $485 \mathrm{~nm}$ and an emission wavelength of $535 \mathrm{~nm}$. Ds-DNA concentration in cell lysates was calculated by comparison against the standard curve. Finally, the cell density per surface area was evaluated normalizing the dsDNA content by the nominal seeding area of each scaffold type, namely $176.625 \mathrm{~mm}^{2}$ (15 mm nominal diameter) for single and dual scale, and $353.250 \mathrm{~mm}^{2}$ (twice the previous area) for triple scale scaffolds.
Normalization by nominal seeding areas took into account that the triple scale scaffold was seeded on both surfaces. This TM scaffold had also received a double quantity of MSCs at seeding, leading to an initially constant cell to surface ratio for all the scaffold types.

\subsubsection{Proteins produced by MSC/scaffold constructs}

The total protein assay was carried out in cascade on the same samples $(n=3)$ used for cellularity quantification. The protein concentration in cellularized samples and acellular controls was determined via the BCA assay using BSA standards at concentrations ranging in $0-1 \mathrm{mg} \mathrm{ml}^{-1}$ and following the microplate procedure. Cell lysates and the working reagent were loaded inside a 96-well microplate at 25 and $200 \mu \mathrm{l}$ per well, respectively. The microplate was incubated for $30 \mathrm{~min}$ at $37^{\circ} \mathrm{C}$. Samples and controls were cooled down to room temperature and absorbance was read at $570 \mathrm{~nm}$ on a plate reader (Victor3). Protein concentration of cellular specimens was obtained by subtracting acellular controls. Finally, total protein was normalized by scaffold surface area as reported above.

\subsubsection{Morphologic analysis of MSC/scaffold constructs via SEM}

For a morphologic characterization of cell-scaffold interactions, MSC/scaffold constructs, one for each type, were fixed in $4 \%$ neutral buffered formalin/PBS solution at $4{ }^{\circ} \mathrm{C}$ overnight. The specimens underwent dehydration through graded ethanol/water solutions up to anhydrous ethanol followed by the critical point method (Balzers CPD030, Oerlikon Balzers, Balzers, Liechtenstein). Dried samples were mounted on aluminum stubs, sputter-coated with gold (Edwards Sputter Coater S150B, Edwards, NY, USA) and examined by SEM using a JEOL JSM-5600 at an accelerating voltage of $10-15 \mathrm{kV}$.

\subsubsection{Cytochemical analysis of MSC/scaffold constructs via methylene blue staining}

Methylene blue is a general stain used to visualize cells against their background. It was used to stain cells and to evaluate their colonization on the patterned scaffolds. One MSC/scaffold construct of each type was fixed in $4 \%$ neutral buffered formalin/PBS solution at $4{ }^{\circ} \mathrm{C}$ overnight. Fixed samples were rinsed in PBS, soaked in a $0.05 \%$ methylene blue solution for $5 \mathrm{~min}$, rinsed with double-distilled water, air dried at room temperature and finally observed with an inverted light microscope (Eclipse TI, Nikon, Tokyo, Japan).

\subsubsection{CLSM analysis of MSC/scaffold constructs}

CLSM was used to investigate cell adhesion, morphology and colonization on the scaffolds. Samples for fluorescence analysis were fixed with $4 \%$ paraformaldehyde overnight, rinsed in PBS and permeabilized 
with Triton $\mathrm{X}-100,0.1 \%$ in PBS for $15 \mathrm{~min}$ under stirring. The constructs were tested with different fluorophores for nuclei and f-actin in order to optimize the imaging method, owing to the fluorescent background of the copolymers. For nuclei, staining was performed either with $0.01 \mathrm{M}$ solution of DAPI or Sytox green for $10 \mathrm{~min}$. For f-actin detection, staining was carried out with either phalloidinAlexa633 or phalloidin-Alexa488 for $45 \mathrm{~min}$ in the dark at room temperature. Images were acquired using a Nikon Eclipse TE2000 inverted microscope equipped with a Nikon EZ-C1 confocal laser and differential interference contrast (Nikon), equipped with a cooled CCD camera (DS-5MC USB2, Nikon), Perfect Focus System, appropriate filters and NIS Elements AR imaging software.

\subsubsection{Histologic analysis}

Dual and triple scale TM constructs $(n=2)$ were processed for histologic analysis to assess cell infiltration in the membrane thickness. It was not feasible to process single scale TM constructs for histology due to crumbling. After washing in $1 \times$ PBS, the constructs were rinsed in $70 \%$ ethanol, dehydrated with a graded series of ethanol/water solutions and incubated in absolute ethanol for $3 \mathrm{~h}$. Finally, the samples were clarified in xylene twice for $45 \mathrm{~min}$. All these processing steps were performed inside a thermostatic bath set to $40^{\circ} \mathrm{C}$. Afterward, the samples were rinsed in liquid paraffin at $60^{\circ} \mathrm{C}$ for $2 \mathrm{~h}$ and paraffin-embedded. The constructs were cross-sectioned using a standard microtome, selecting representative sections every $200 \mu \mathrm{m}$ of microtome advancement. In this way, representative thicknesses, from the periphery to the center of the TM constructs, were analyzed. Hematoxylin and eosin staining was thus performed following the standard protocol routinely used in the anatomic pathologist laboratories. The sections were mounted with a DPX mounting agent and ultimately observed with a DMRB Leica microscope (Leica Microsystems, Wetzlar, Germany), capturing micrographs at $40 \times$ and $63 \times$ original magnifications.

\subsection{Statistical analysis}

Quantitative data were presented as descriptive (mean \pm standard deviation (SD)) and inferential statistics ( $p$ values). For scaffold characterization, data sets were screened by one-way ANOVA, and a Tukey test was used for post hoc analysis. Significance was set at $p<0.05$. Statistical significance in biochemical analyses was evaluated using the two-tailed t-test for either paired (alamarBlue assay ${ }^{\circledR}$, intra-series comparisons) or unpaired (alamarBlue ${ }^{\circledR}$ assay, inter-series comparisons; ds-DNA and total protein content assays) data, followed by Bonferroni-Holm correction.

\section{Results}

\subsection{Single scale patterned TM scaffolds}

SEM analysis of the meshes showed that diverse fiber morphology and alignment were obtained in different scaffold regions and highlighted the capability of the collector to create macropatterns (figures 4(a) and (c)). Although the fibers were randomly disposed at the microscale level, they chiefly gathered along the collector rays, thus resulting in mesh-thickening patterns at the macroscale level. However, this patterning effect was lost if spinning times of $3 \mathrm{~min}$ or longer were applied (figures 4(b) and (d)).

Mesh thickness was $24.61 \pm 8.15$ and $19.37 \pm 12.20 \mu \mathrm{m}$, while the fiber diameter was $1.4 \pm 0.5$ and $1.8 \pm 0.6 \mu \mathrm{m}$, for 1 and 2 min collection times, respectively (table 2 ). In both cases no statistically significant differences were detected between collection times $(p>0.05)$. Profilometric analysis was able to determine the maximum height of the patterning elements, namely the outer border and the radii (table 2). The maximum heights of the outer border were $23.19 \pm 5.97$ and $68.90 \pm 19.16 \mu \mathrm{m}$, and those of the radii were $26.22 \pm 12.71 \mu \mathrm{m}$ and $49.53 \pm 13.10$, for 1 and 2 min collected meshes, respectively. A collection time of $1 \mathrm{~min}$ was selected as the optimal to fabricate single scale TM scaffolds.

\subsection{Dual and triple scale patterned TM scaffolds}

A second approach aimed at optimizing the mechanical stability of the TM scaffolds was developed by combining ES and AM (figure 3). Two TM scaffolds based on the PEOT/PBT copolymer were designed and successfully produced via different manufacturing scales (i.e., dual and triple) with a multi-step approach (figures 3(a) and (b). The underlying reason using PEOT/PBT for dual and triple scale scaffolds relies on the AM equipment set up and optimized for this copolymer. The first step comprised of the production of patterned fiber layers, arranged as grids, to be coated with an electrospun mesh. Two scaffold designs were manufactured (i) with the electrospun mesh that coated the radial and circular patterns, manufactured as a single piece (namely, dual scale TM scaffolds) (figure 3(e)), and (ii) with the electrospun mesh placed in between the radial and circular patterns, manufactured as two separated pieces (namely, triple scale TM scaffolds) (figure 3(f)). These patterned grids, produced by means of 3DF, were built with a deposition velocity of $56 \mathrm{~mm} \mathrm{~min}^{-1}$ leading to a fiber diameter of $352 \pm 32 \mu \mathrm{m}$ (figures 5(a), (c) and (d)).

As a preliminary step before complete scaffold assembly, morphology and thickness of the electrospun fibers were investigated. For this optimization phase, a solution of PEOT/PBT was used as previously reported by Moroni et al [28]. The processing parameters were optimized as follows: feeding rate $(F) 5 \mathrm{ml} \mathrm{h}^{-1}$, spinneret-to-collector distance 

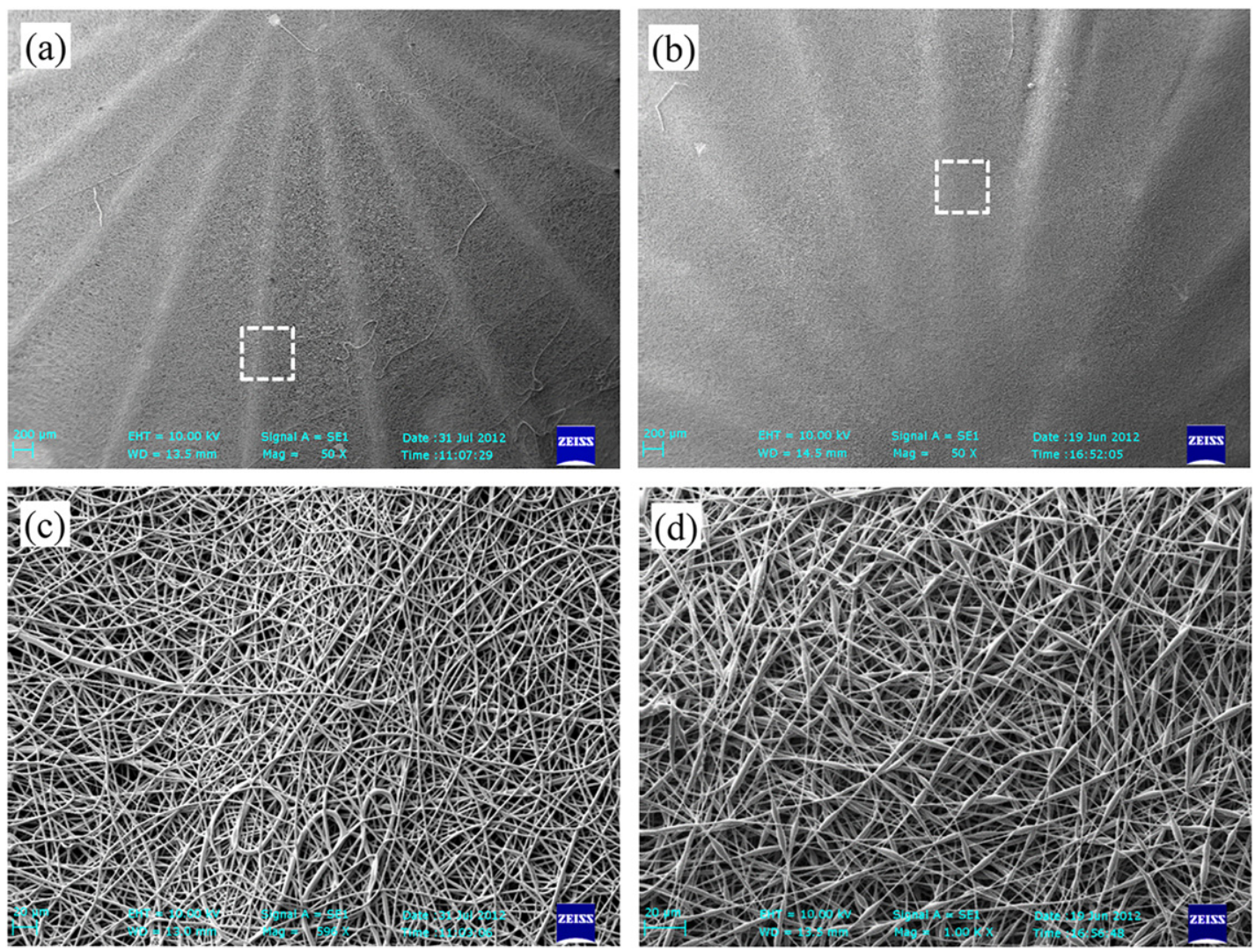

Figure 4. SEM micrographs of single scale TM scaffolds: PLGA electrospun mesh collected on top of a custom-made collector at different times: (a) and (c) after $1 \mathrm{~min}$; (b) and (d) after 5 min. Images (c) and (d) represent the zoomed in regions indicated in (a) and (b), respectively. Scale bar in (a) and (b) is $200 \mu \mathrm{m}$; and in (c) and (d) $20 \mu \mathrm{m}$.

Table 2. Characteristics PLGA and PEOT/PBT electrospun TM scaffolds obtained at different collection times. Measurements were performed in five different areas of the samples $(n=3)$. Values are presented as mean \pm SD.

\begin{tabular}{lccccc}
\hline Copolymer & \multicolumn{2}{c}{ PLGA } & \multicolumn{3}{c}{ PEOT/PBT } \\
\hline Collection time $(\mathrm{s})$ & 60 & 120 & 30 & 60 & 120 \\
Fiber diameter $(\mu \mathrm{m})$ & $1.8 \pm 0.6$ & $1.4 \pm 0.5$ & $1.8 \pm 0.5$ & $2.0 \pm 0.6$ & $2.1 \pm 0.7$ \\
Mesh thickness $(\mu \mathrm{m})$ & $24.61 \pm 8.15$ & $19.37 \pm 12.20$ & $44 \pm 19$ & $95 \pm 15$ & $146 \pm 35$ \\
Pattern height $(\mu \mathrm{m}):$ & & - & $352 \pm 32$ & $352 \pm 32$ & $352 \pm 32$ \\
- Grid fiber & - & - & - & - & - \\
- Outer borders & $23.19 \pm 5.97$ & $68.90 \pm 19.16$ & - & - & - \\
- Inner radii & $26.22 \pm 12.71$ & $49.53 \pm 13.10$ & - & \\
\hline
\end{tabular}

$\left(d_{3}\right) 15 \mathrm{~cm}$, and applied voltage $\left(V_{\text {app }}\right) 15 \mathrm{kV}$. Such working parameters were maintained for all the conducted experiments. The thickness of the electrospun meshes varied according to collection time. For the optimization of mesh thickness, three collection times were evaluated: 30,60 and $120 \mathrm{~s}$. The results of the electrospun mesh thickness are reported in table 2. According to the measured values a collection time between 30 and $60 \mathrm{~s}$, leading to mesh thickness of $44 \pm 19$ and $95 \pm 15 \mu \mathrm{m}$, respectively, resulted suitable to match the thickness of human TMs, which has been reported to range in $30-100 \mu \mathrm{m}$ [1]. A 120 s collection time gave rise to a $146 \pm 35 \mu \mathrm{m}$ thick mesh. Considering the grid layers to be subsequently added, a collection time of $30 \mathrm{~s}$ was selected as the optimal for this application. SEM analyses showed homogeneous ultrafine fiber morphology for all the produced meshes with a fiber diameter ranging from $1.8 \pm 0.5$ (at $30 \mathrm{~s}) \mu \mathrm{m}$ to $2.1 \pm 0.7$ (at $120 \mathrm{~s}) \mu \mathrm{m}$ (table 2). This small variation in the ultrafine fiber diameter was not statistically significant $(p>0.05)$.

Results of pore size evaluation in copolymer meshes are reported in table 3 . Pore size and distribution in the PEOT/PBT mesh used for dual and triple scale TM scaffolds were evaluated via MIP, investigating pore sizes ranging in $0.003-300 \mu \mathrm{m}$. This analysis showed that the largest volume percentage was filled by pores with diameters ranging in $3-10 \mu \mathrm{m}(32.0 \%)$ and $10-30 \mu \mathrm{m}$ $(31.6 \%)$, which on the whole accounted for $63.6 \%$ of relative pore volume. The rest of the void volume 

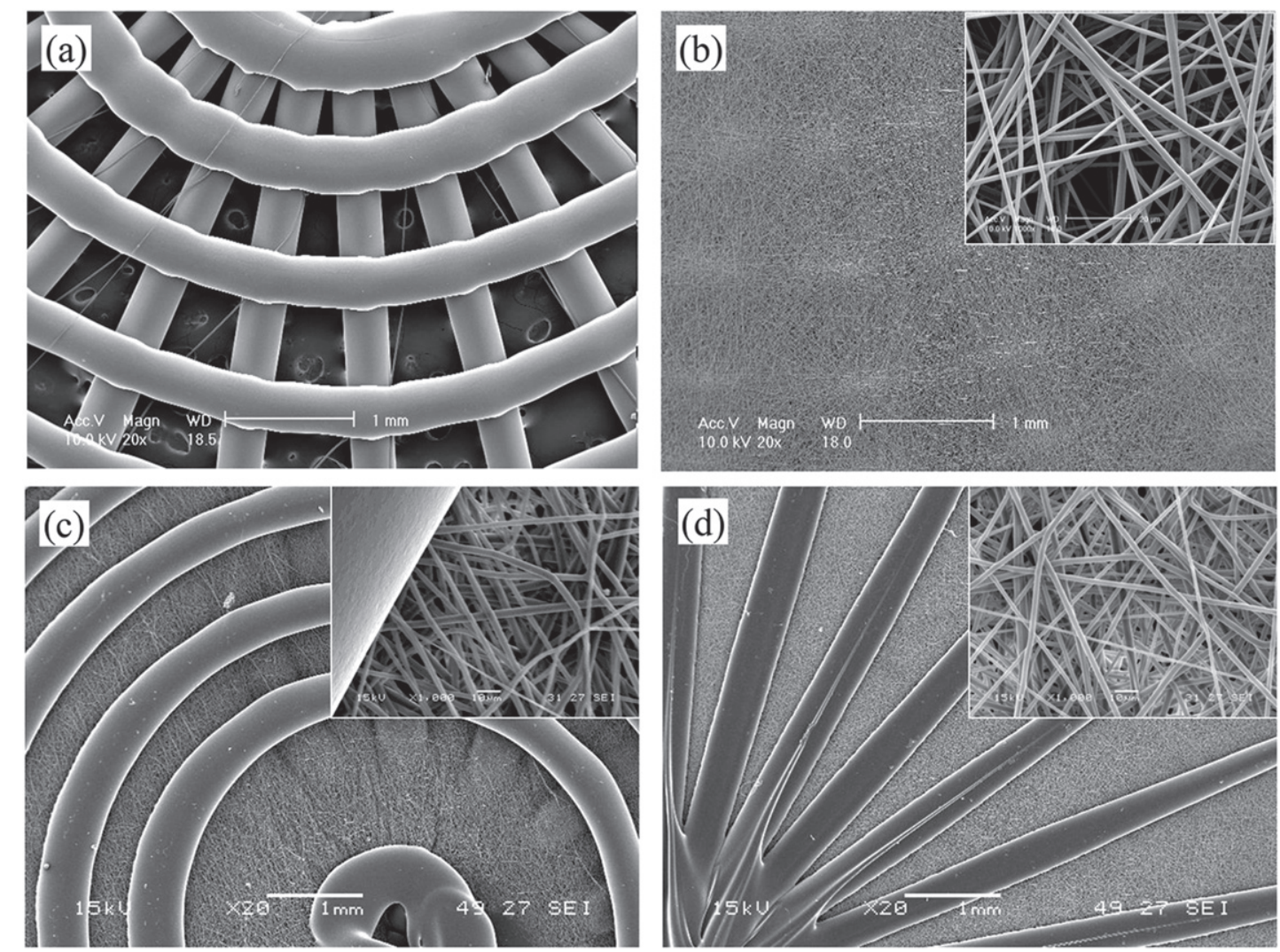

Figure 5. SEM micrographs of the dual and triple TM scaffold: (a) microfiber pattern produced by means of AM technique; (b) electrospun mesh collected during $30 \mathrm{~s}$ on top of the microfiber pattern; (c) triple TM scaffold observed from the side of concentric micro-patterns; and (d) triple TM scaffold observed from the radial micro-pattern. Insets on (b)-(d) refer to details of the electrospun fiber morphology, scale bar is $10 \mu \mathrm{m}$.

Table 3. Relative pore volume percentage of PEOT/PBT and PLGA electrospun meshes are reported for different pore size classes. Measurements were performed via MIP for PEOT/PBT $(n=2)$ and via image analysis for PLGA scaffolds $(n=3)$. Average values are presented. 'N/a' indicates undetectable values due to inherent limits of the measurement technique.

\begin{tabular}{|c|c|c|c|c|c|c|c|c|c|c|}
\hline \multirow[b]{2}{*}{$\mathrm{PEOT} / \mathrm{PBT}$} & \multicolumn{10}{|c|}{ Relative pore volume \% } \\
\hline & 0.2 & 1.8 & 0.2 & 1.6 & 3.4 & 9.4 & 32.0 & 31.6 & 19.7 & - \\
\hline PLGA & $\mathrm{n} / \mathrm{a}$ & $\mathrm{n} / \mathrm{a}$ & $\mathrm{n} / \mathrm{a}$ & $\mathrm{n} / \mathrm{a}$ & $\mathrm{n} / \mathrm{a}$ & 0.3 & 43.6 & 56.1 & $\mathrm{n} / \mathrm{a}$ & $\mathrm{n} / \mathrm{a}$ \\
\hline Pore size ranges $(\mu \mathrm{m})$ & $0.003-0.01$ & $0.001-0.03$ & $0.03-0.1$ & $0.1-0.3$ & $0.3-1$ & $1-3$ & $3-10$ & $10-30$ & $30-100$ & $100-300$ \\
\hline
\end{tabular}

resulted fractioned as follows: $19.7 \%$ by $30-100 \mu \mathrm{m}$ diameter pores, $9.4 \%$ by $1-3 \mu \mathrm{m}$ diameter pores, while the complimentary volume percentage was in charge of micropores with size lower than $1 \mu \mathrm{m}$. The pore class $100-300 \mu \mathrm{m}$ did not account for any pore volume. Differently from MIP, the image analysis technique used for single scale TM scaffolds showed inherent limits to detect both small and large diameter pores, the latter likely deriving from void areas defined by fibers placed on a slightly different $z$ plane from those of underlying fiber network. The outcomes of this image analysis showed that $56.1,43.6$ and $0.3 \%$ of the pore volume were seized by pores with diameters ranging in 10-30, $3-10$ and $1-3 \mu \mathrm{m}$ pore classes, respectively. From the obtained measurements, the pores having 3-30 $\mu \mathrm{m}$ diameters could be accurately detected, being the 10-30 $\mu$ m class the most represented.

\subsection{Biological evaluation}

To assess suitability of differently scaled TM scaffolds for TE application, the three scaffold types were seeded with human MSCs using equal density of viable cells per patterned area and cultured in vitro for 8 days. The results of biochemical assays are reported in figure 6 . The alamarBlue ${ }^{\circledR}$ assay was used to monitor the metabolic activity of cells along the culture time as a proof of their viability (figure 6(a)). In single scale scaffold/MSC constructs, $\% \mathrm{AB}_{\text {red }}$ was $8.99 \pm 2.25$, $11.50 \pm 4.04$ and $12.18 \pm 2.75 \%$, on days 2,5 and 8 , respectively. Statistical analysis showed that the initial cell viability was maintained during culture time ( $p>0.05)$. In dual scale scaffold/MSC constructs, $\%$ $\mathrm{AB}_{\text {red }} \quad$ was $18.71 \pm 5.23, \quad 27.15 \pm 6.64$ and $26.03 \pm 6.68 \%$, on days 2,5 and 8 , respectively. Statistical analysis demonstrated a general increase in 
(a)

\section{Cell viability}

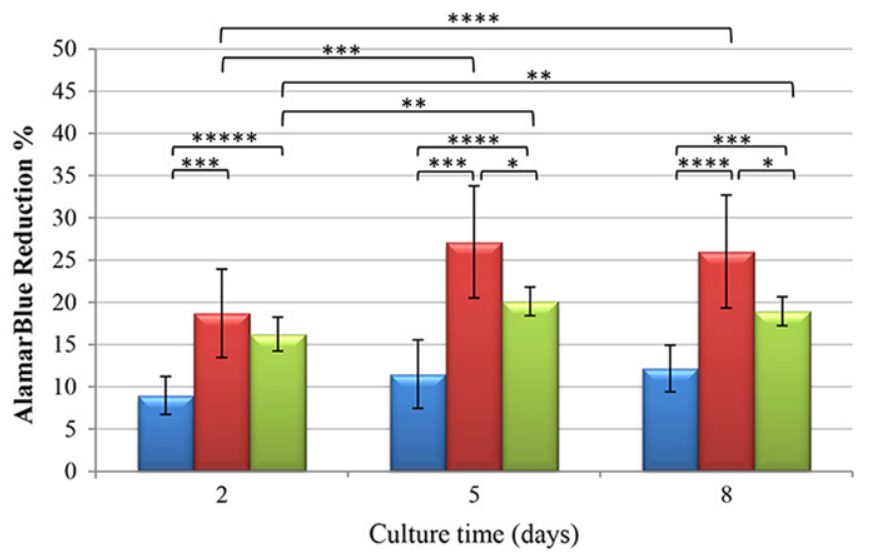

$\square$ Single scale

D Dual scale

$\square$ Triple scale

(b)

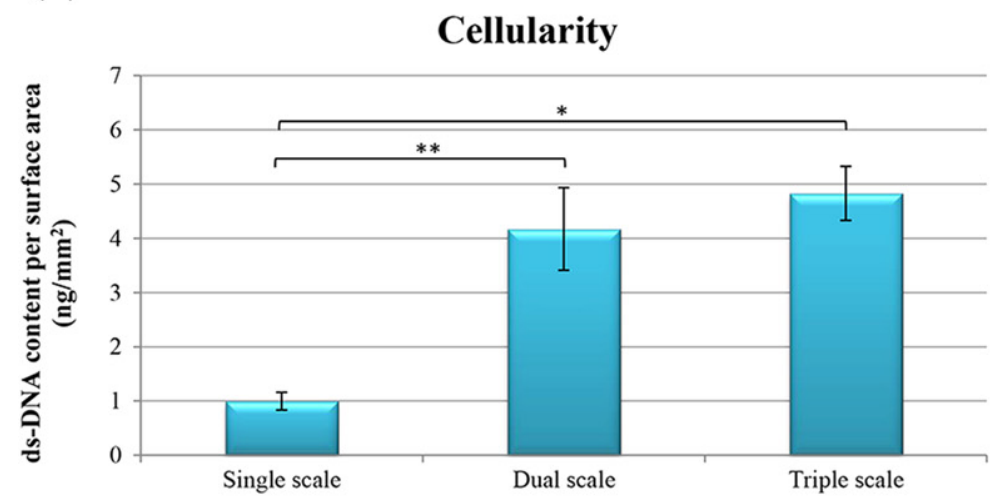

(c)

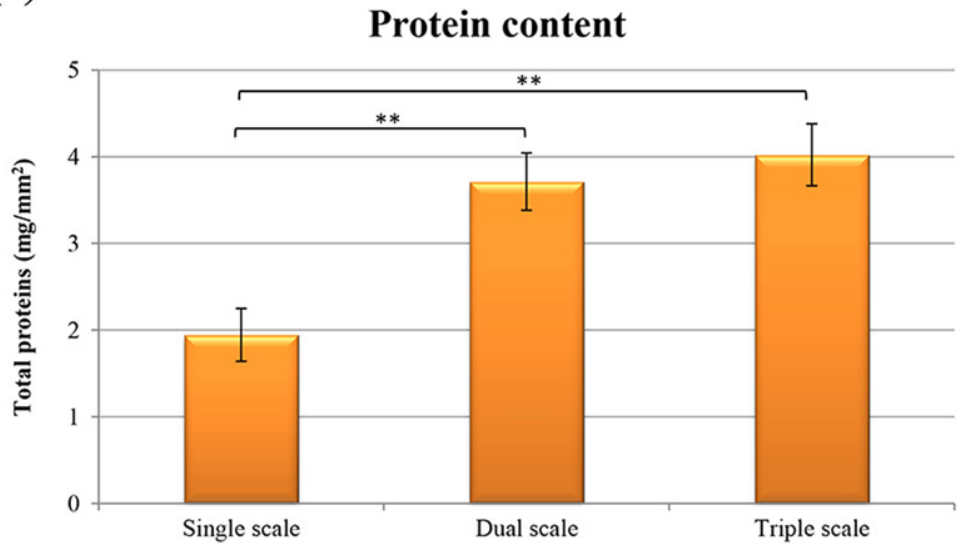

Figure 6. Bar graphs showing: (a) viability of human MSCs cultured on different TM scaffolds up to 8 culture days; (b) cellularity of the MSC/scaffold constructs at the endpoint; (c) content of total proteins produced by MSCs in the scaffolds at the endpoint. Data are reported as mean $\pm \mathrm{SD}$; asterisks indicate the following magnitude orders of $p$ values: ${ }^{\star} 10^{-2} ;^{\star *} 10^{-3} ;{ }^{\star * *} 10^{-4} ;{ }^{\star * * *} 10^{-5}$ and ${ }^{\star * * * *}$ $10^{-6}$

cell viability along the culture time (days 2 versus 5 : $p=0.0003$; days 5 versus $8: p>0.05$; days 2 versus 8 : $p=0.00005)$. In triple scale scaffold/MSC constructs, $\% \mathrm{AB}_{\text {red }}$ was $16.25 \pm 2.00,20.12 \pm 1.69$ and $18.95 \pm 1.71 \%$, on days 2,5 and 8 , respectively. Similarly to the dual scale constructs, statistical analysis highlighted both an initial $(p=0.008)$ and an overall ( $p=0.002)$ increase in cell viability, while no differences were detected between days 5 and 8 $(p>0.05)$. At the same time-points, statistically significant differences in cell viability for different scaffold types were detected, but in dual scale versus triple scale on day 2. In particular, the strongest statistically significant differences in cell viability were found between single scale and dual scale constructs $(p=0.0003, p=0.00003$, and $p=0.0001 ;$ on days 2,5 and 8 , respectively) and between single scale and triple scale constructs $(p=0.000002, p=0.0001$, and 

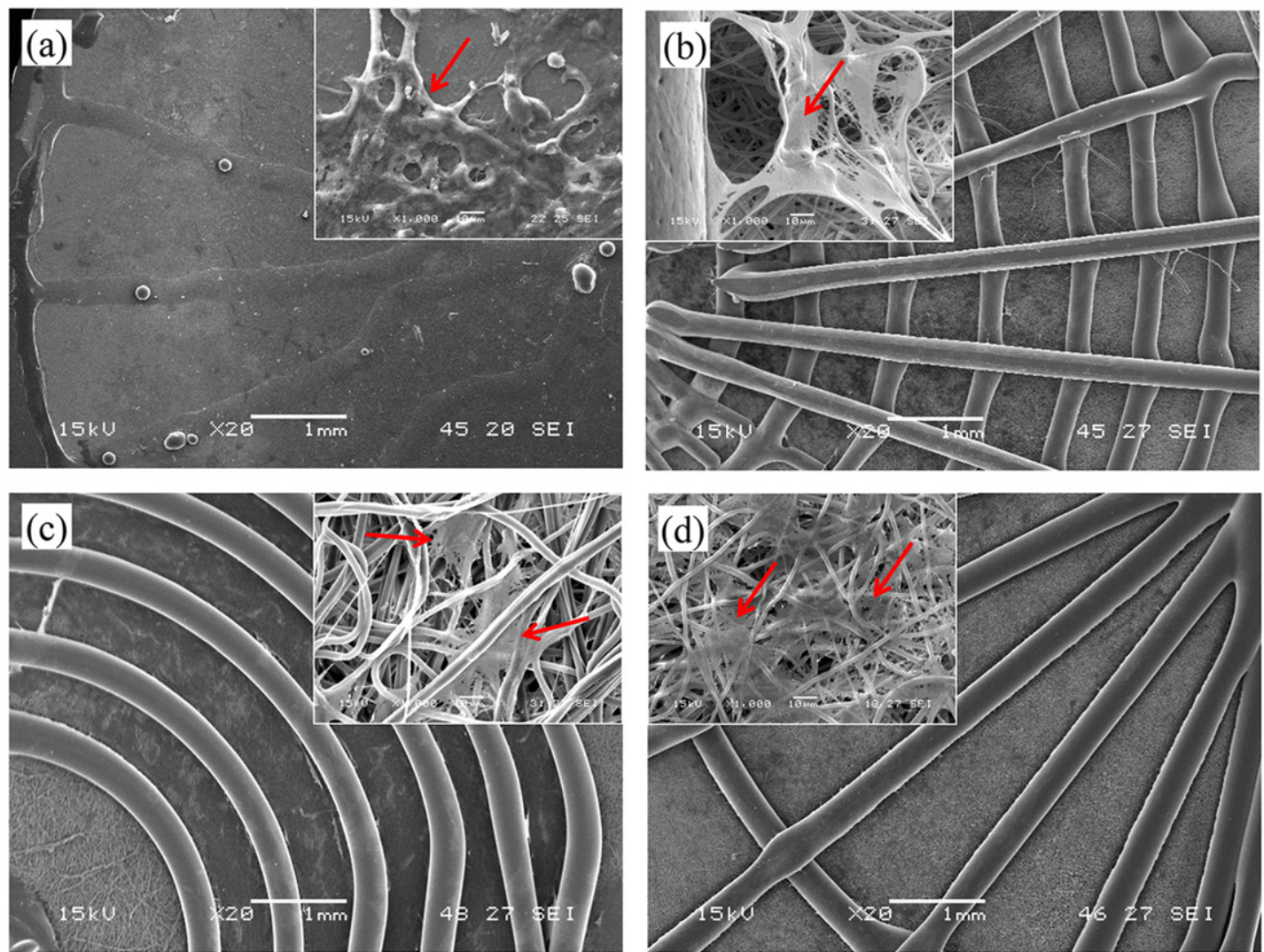

Figure 7. SEM micrographs of human MSC/TM scaffold constructs at the endpoint: (a) single scale; (b) dual scale; (c) triple scale, circular pattern side; and (d) triple scale, radiate pattern side. (a)-(d) Insets reveal cell details showing how MSCs interact with the scaffolds, scale bar is $10 \mu \mathrm{m}$.

$p=0.00002$; on days 2,5 and 8 , respectively). Statistical significance was highlighted only al late timepoints $(p>0.05, p=0.01$, and $p=0.01$; on days 2,5 and 8 , respectively) in comparisons between dual scale and triple scale constructs. The final cellularity per surface area of the scaffolds was measured as a function of the ds-DNA content using the PicoGreen assay (figure 6(b)). This normalization was performed to take into account that the three scaffolds were seeded with surface-proportional cell densities; in particular because the triple scale scaffolds were seeded on both surfaces. On day 8, ds-DNA content resulted $1.00 \pm 0.16 \mathrm{ng} \mathrm{mm}^{-2}$ in single scale, $4.17 \pm 0.76 \mathrm{ng} \mathrm{mm}^{-2}$ in dual scale and $4.82 \pm 0.50 \mathrm{ng} \mathrm{mm}^{-2}$ in triple scale constructs, indicating a statistically significant difference of single scale against dual scale $(p=0.003)$ and triple scale constructs $(p=0.02)$. No difference was detected between dual and triple scale constructs $(p>0.05)$. Finally, the total protein amount produced by MSCs in each construct type was determined using the BCA assay. The data were normalized per scaffold area (figure 6(c)). At the endpoint, protein content resulted $1.94 \pm 0.30 \mathrm{ng} \mathrm{mm}^{-2}$ in single scale, $3.71 \pm 0.33 \mathrm{ng} \mathrm{mm}^{-2}$ in dual scale and $4.02 \pm 0.36 \mathrm{ng} \mathrm{mm}^{-2}$ in triple scale constructs, indicating a statistically significant difference of single scale against dual scale $(p=0.003)$ and triple scale constructs $(p=0.002)$. No difference was detected between dual and triple scale constructs $(p>0.5)$.

A morphologic analysis of MSC/scaffold constructs was performed via SEM (figure 7).

Micrographs of single scale TM constructs showed that the shape and morphology of the scaffolds were maintained after culture, although slight changes in radial pattern topography occurred and the construct resulted very delicate at handling (figure 7 (a)). Cells adhered as a layer to the scaffold weave, but were not fully stretched out (figure 7 (a), insert). Differently, dual and triple scale TM scaffolds were found to be more robust than single scale ones showing stable pattern topography after culture (figures $7(\mathrm{~b})-(\mathrm{d})$ ). In both dual and triple scale scaffolds, the MSCs were able to adhere to the electrospun mesh and to intercalate within the ultrafine fibers with a completely stretched out morphology availing itself of several anchoring points, and generating an intrinsically biohybrid membrane (figures $7(\mathrm{~b})-(\mathrm{d})$, inserts). In the dual and triple scale scaffolds, many cells were found to connect the electrospun mesh with the AM patterned grid, thus enhancing the cohesion within the bioconstruct. An example of cell spreading across the grid layer is reported in the insert of figure 7 (b). 


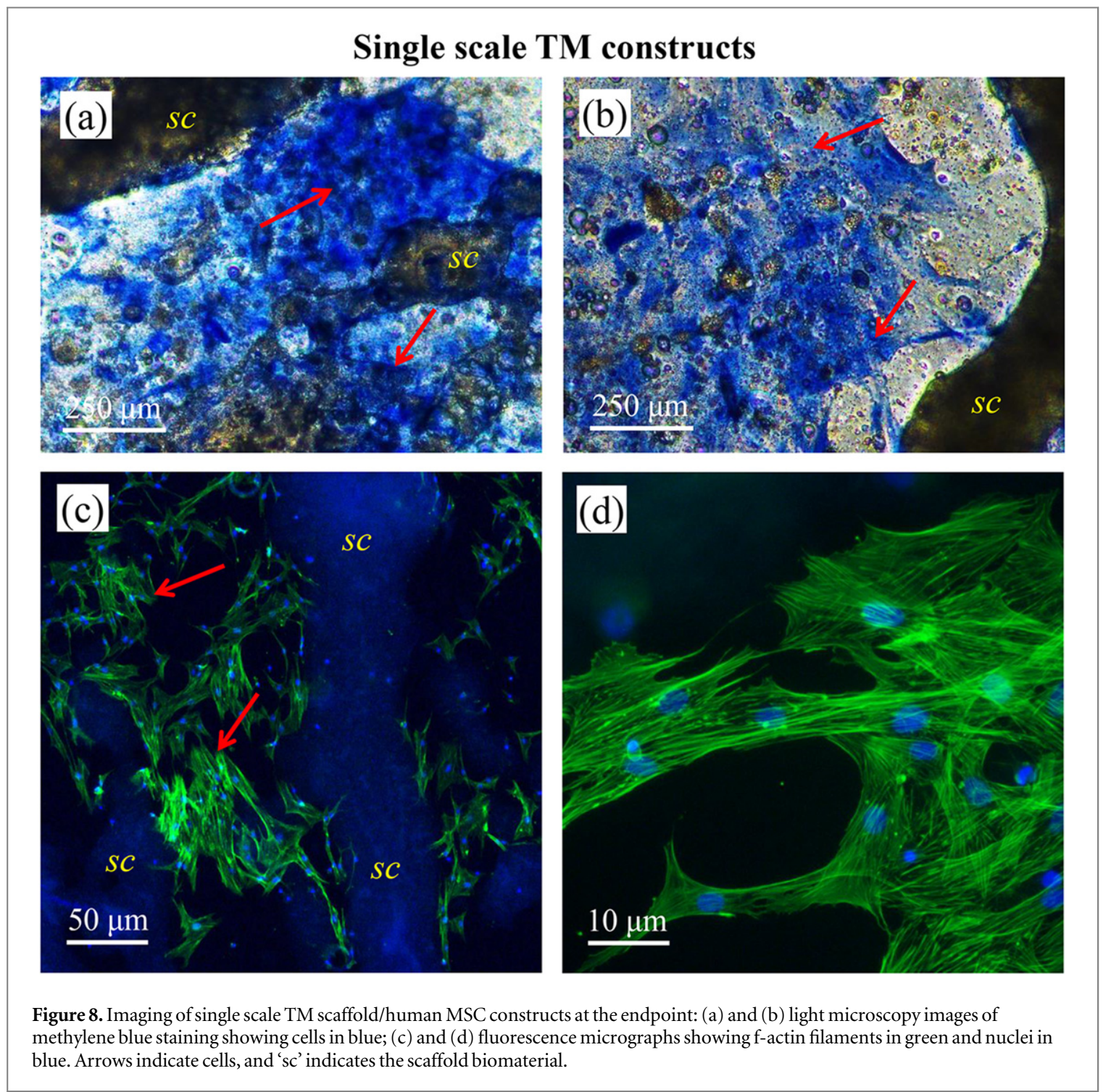

Single scale scaffolds were assayed via basic cytochemical and fluorescent staining to trace the topography of cell colonization along the radial patterns (figure 8). Methylene Blue staining highlighted cells that spread out on the scaffold weave and that showed some inhomogeneity (figures 8(a) and (b)). Interactions with the patterned (i.e., thicker) copolymer profiles appeared to be reduced with respect to the base mesh (figure 8 (b)). CLSM analysis highlighted MSCs expressing well-developed f-actin (figure $8(\mathrm{~d})$ ) and confirmed that cells were located on the scaffold radii only occasionally (figure $8(\mathrm{c})$ ), preferring self-aggregation (figure $8(\mathrm{~d})$ ).

Imaging of dual scale TM scaffold/MSC constructs via CLSM is summarized in figure 9. The web-like grid allowed cell confinement within trapezoid spaces of different areas, mimicking the umbo zone. The topography of cell disposition was highlighted imaging the cell nuclei in green (figure 9(a)). In the central area of the constructs, the cells followed very precise circular and radial outlines, showing an elongated cytoskeleton, as demonstrated by f-actin filaments in red (figure 9(b)). All the trapezoid interspaces between the grid were filled with cells, both the small (closer to the center) (figure 9(d)) and the large (closer to the periphery) (figure 9(c)) ones. Here, the orientation of MSCs was isotropic and f-actin was well expressed. Figure $9(\mathrm{e})$ confirmed that cells infiltrated inside the electrospun mesh and were connected with several ultrafine fibers.

The triple scale TM scaffold/MSC constructs were imaged on both the radial and circular side, in central or peripheral areas, both at a macro- and micro-scale level (figure 10). Cell arrangement along the directional grooves was efficiently imaged with Methylene Blue staining (figures 10(a), (b), (d) and (e)), while LCSM allowed cellular details to be highlighted (figures 10(c) and (f)). Viable MSCs at high density were found in any area of the scaffolds, following both the radial (figures $10(\mathrm{a})$ and (b)) and the circular (figures $10(\mathrm{~d})$ and (e)) patterns and connecting with the grids, thus creating homogenous cellular layers on the scaffolds (figures 10(a), (b), (d) and (e)). The MSCs were highly stretched out on each side of the 


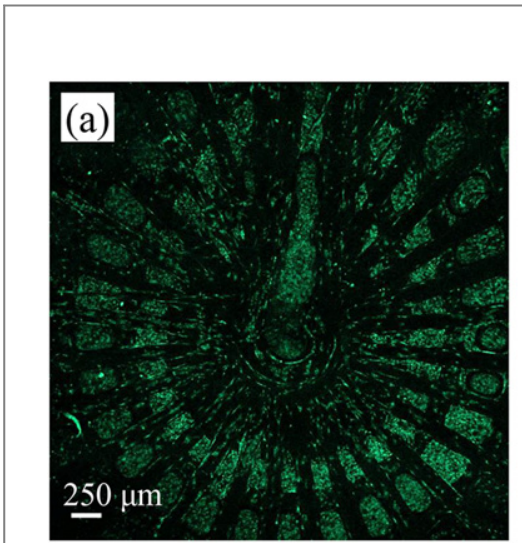

Dual scale TM constructs
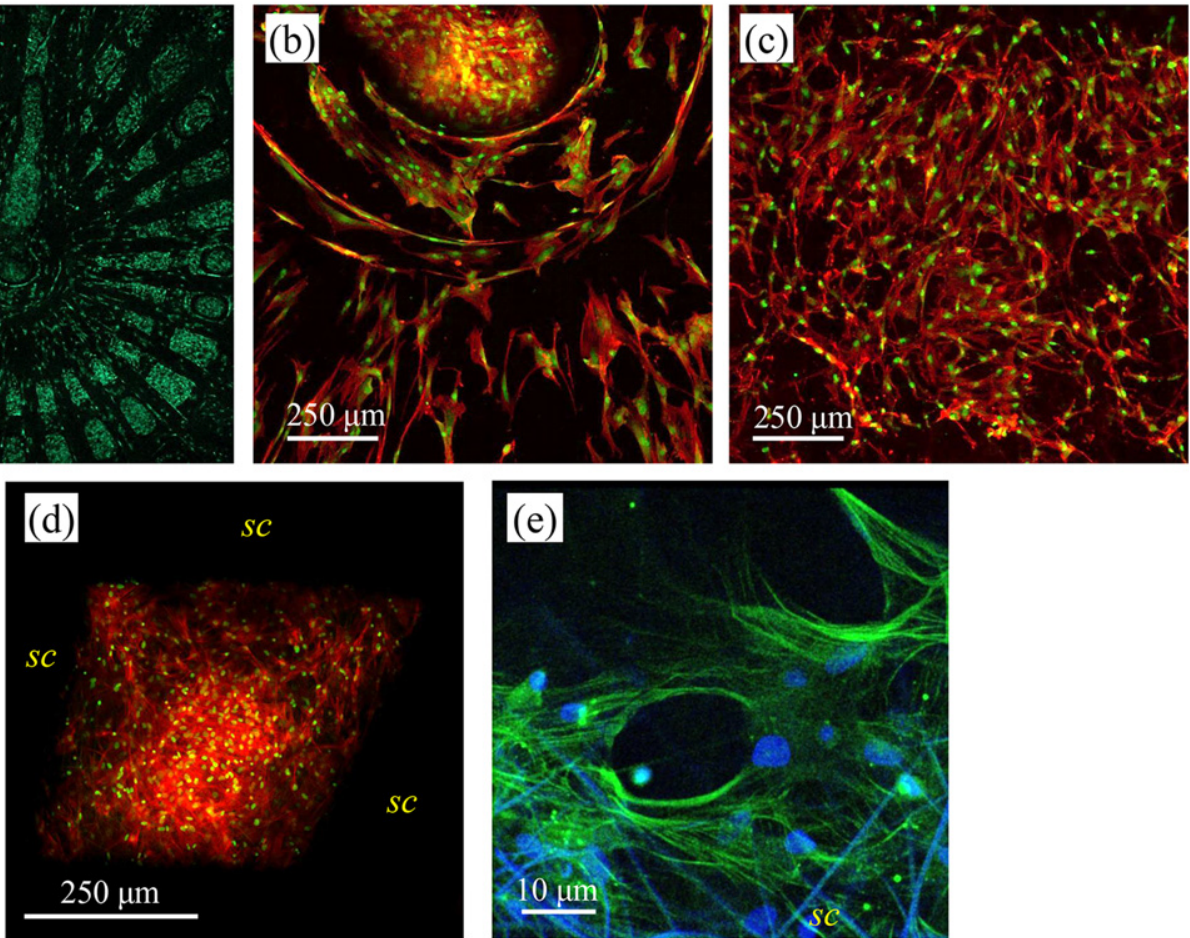

Figure 9. Imaging of dual scale TM scaffold/human MSCs constructs at the endpoint via CLSM: (a) a zoomed-out micrograph of cell nuclei in green; (b)-(d) zoomed-in images of different areas showing f-actin filaments in red and nuclei in green; and (e) a high magnification micrograph showing cells interacting with electrospun fibers, $\mathrm{f}$-actin in green and nuclei in blue; 'sc' indicates the scaffold biomaterial.

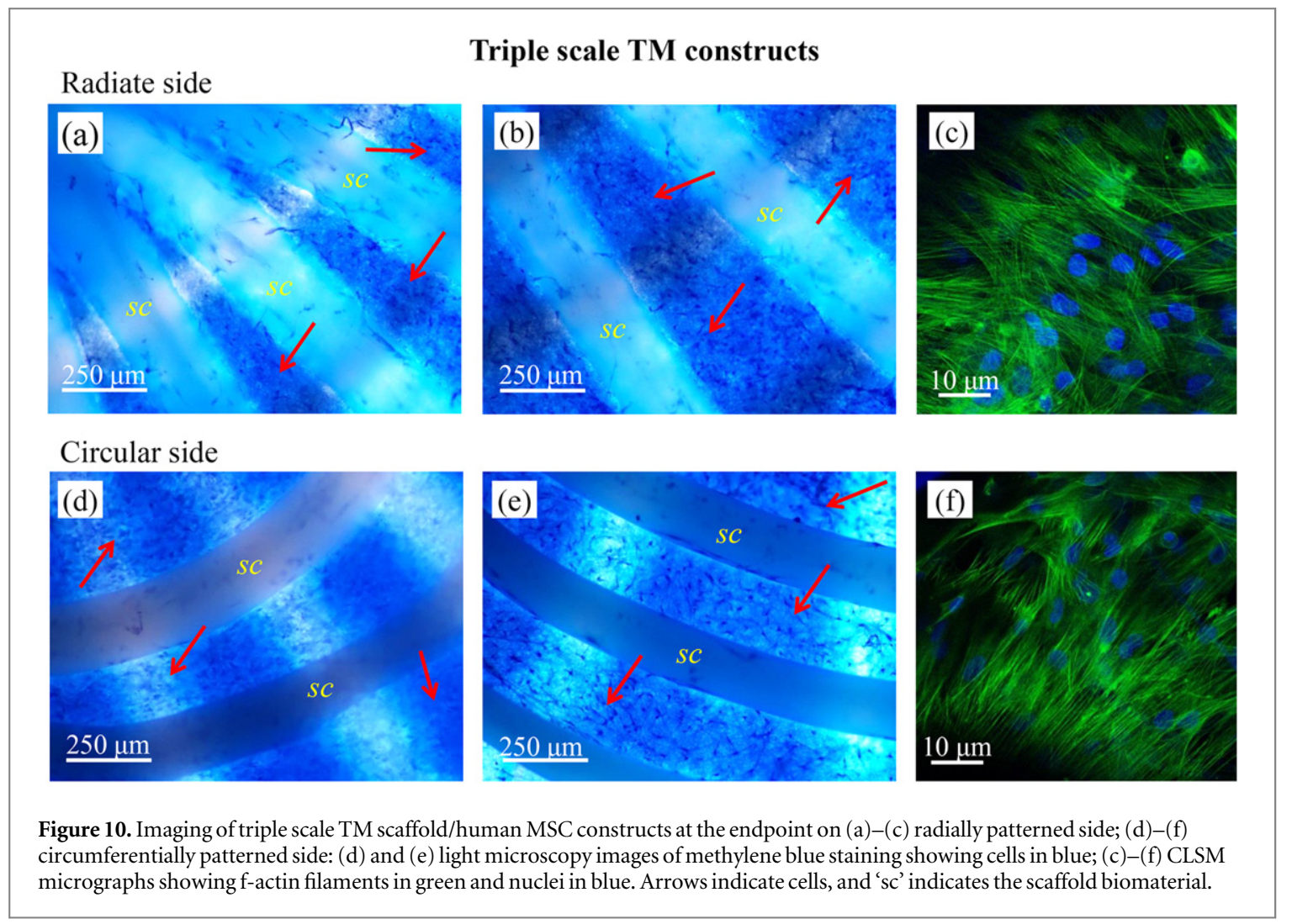

membrane, and a number of cell domains expressed $\mathrm{f}$ actin along anisotropic directions following the pattern orientation (figures $10(\mathrm{~d})$ and $(\mathrm{e})$ ).
In all the construct types, the cell nuclei looked well preserved, without chromatin condensation, thus indicating the absence of relevant apoptotic 

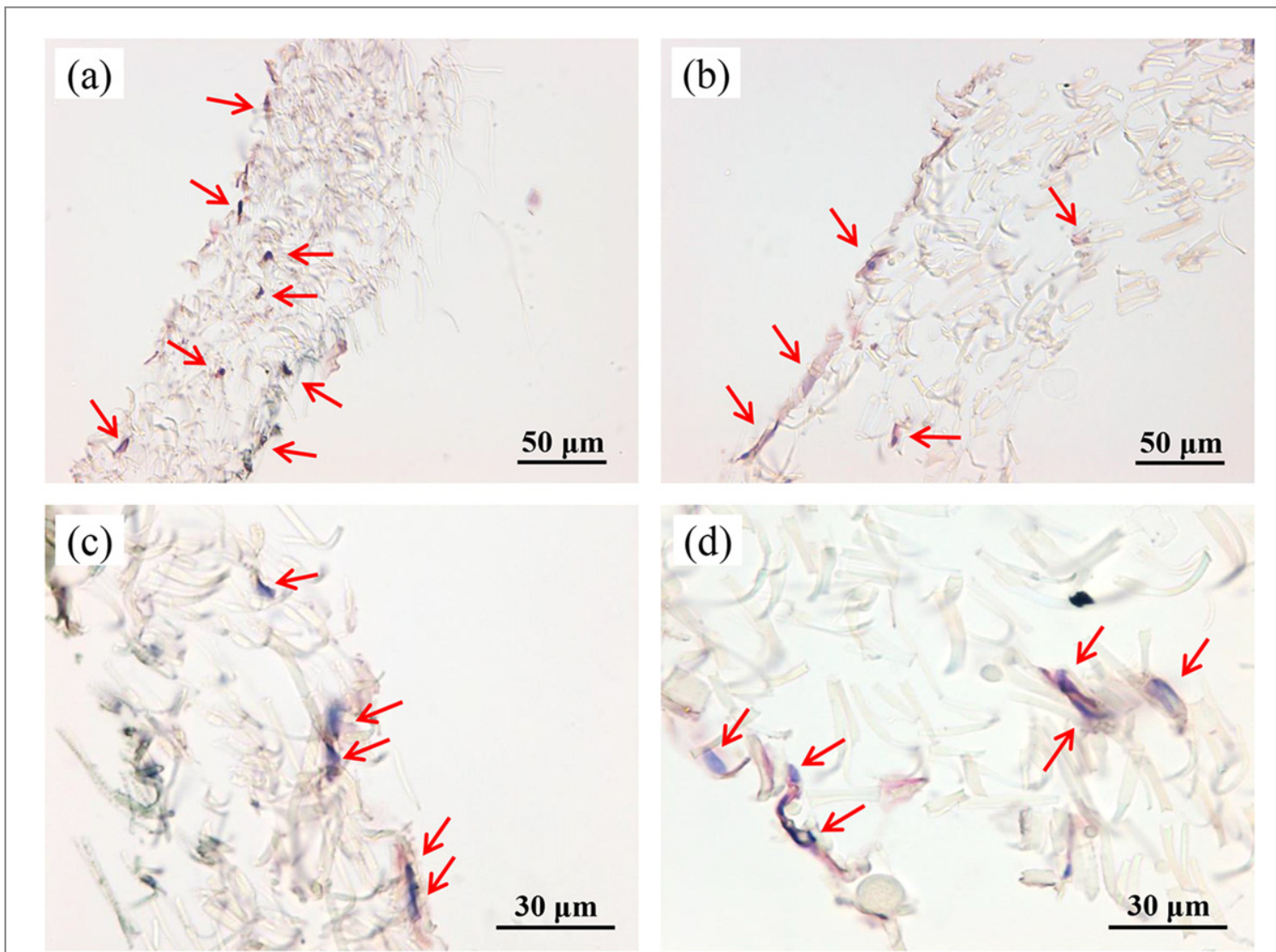

Figure 11. Histologic micrographs of dual and triple scale TM scaffold/MSC constructs at the endpoint showing cell infiltration into the mesh thickness: (a) and (c) dual scale constructs; (b) and (d) triple scale constructs. (a) and (b) 40× original magnification micrographs; (c) and (d) zoomed in details of $63 \times$ original magnification micrographs (final magnification $100 \times$ ). Arrows indicate cells both layering and penetrating the mesh thickness.

phenomena induced by the materials. On the whole, no signs of injury or necrosis were observed in MSCs after 8 day cultures with the manufactured TM scaffolds.

MSC infiltration into the thickness of dual and triple scale TM scaffolds was analyzed via histology (figure 11). In both construct types, the cells were found to adhere as monolayers covering the external surface of the meshes (figures 11(a)-(d)). Evidence of cell penetration inside (figures $11(\mathrm{a}),(\mathrm{b})$ and (d)) and across (figures 11(a) and (b)) the mesh thickness was also documented.

\section{Discussion}

The clinical and experimental application of TE principles to remote spare parts of the human body, such as the middle ear, is still poorly addressed, even if otologists are looking at the future with great expectations [35]. The underlying reason for such a late development of TE products for sensory organs probably relies on the extreme specialization of their tissues, which has challenged successful in vitro strategies for their regeneration. The middle ear is an anatomic compartment devoted to sound collection and mechanic transmission, in which the shape and histo-anatomic features of tissues play an essential role in gaining high efficiency under physiologic constraints [3]. Although several unspecific grafts or biomaterials have shown sufficient capacity to heal eardrum perforations and restore the mechanic connection indispensable for sound transmission throughout the middle ear, the optimal TM replacement has not yet been achieved. Further improvements are necessary in regard to the quality of the post-surgical hearing, which could benefit from nature-inspired bioprostheses [35]. It is a fact that the lesions of the eardrum are a widespread pathology leading to conductive hearing loss for which reconstructive surgery represents the only option [9-12]. To this end, advanced TE strategies enabling the manufacturing of complex scaffolds can be exploited for the biofabrication of middle ear substitutes, considering that they are so small and complex [36]. The key requirements needed by TM replacements have been summarized by Teh et al in the first review article on eardrum TE [13]. These authors have identified some specific characteristics for ideal TM grafts, including transparency to monitor TM healing and resistance to deformations induced by pressure variations, along with a number of basic requisites necessary to TM scaffolds, namely, non-toxicity, high porosity, biodegradability, mechanical strength/deformation, ability 
to promote adhesion, growth and function of cells and off-the-shelf availability [13]. It is extremely important to define appropriate guidelines about design criteria for TM scaffolds in order to reach successful TE products for otologic surgery. However, due to the currently limited number of studies on this subject, the guidelines will be tuned to new research outcomes and approaches.

In this report, we showed the application of advanced scaffolding technologies to fabricate anatomy inspired TM replacements based on two FDAapproved copolymers of wide biomedical use, namely PLGA and PEOT/PBT. We aimed at refining and combining existing technologies, such as ES and AM, to manufacture TM scaffolds with specific radial and/or circular patterning obtained by means of microgrooves. Such biomimetic patterned membranes were designed to fulfill general scaffolding requirements, as described by Teh and coworkers [13]; moreover, they were supposed to guide the disposition of human MSCs along the directions created by the grooves. Arranging the cells on the TM scaffolds along predetermined architectural pathways may eventually determine the zonal production of collagen and other ECM molecules by TM cells. Indeed, the complex architecture of radial and circumferential collagen fibers of the pars tensa, combined with tissue characteristics, such as size and shape, enable the fine biomechanics of the TM [3]. Cell ES is an all-in-one technique, potentially suitable to prepare cellularized single scale TM scaffolds ready to use, which deserves future exploration $[23,24]$. Differently, our approach was designed across separate steps to enable AM implementation. In this view, the obtained biomimetic topography is the leading strategy to localize the cells within predefined radial and/or circular areas. The accomplishment of this goal would be a crucial step to target functional eardrum replacements of putative surgical interest.

The specific aims of our study included the proof of feasibility of fabricating patterned TM scaffolds via multiscale manufacturing methods of increasing complexity (single, dual and triple scale) and a preliminary in vitro evaluation of the produced scaffolds using human MSCs to assess their cytocompatibility and capability of topographical cell arrangement. The application of stem cells, such as MSCs, for the treatment of TM perforations was first proposed by Rahman et al and showed good results in a rat model [6]. Regenerating a bioengineered TM with MSCs is also legitimated by developmental biology [37]. From an embryologic point of view, TM has a triple origin that includes endodermal, mesodermal and ectodermal components [38]. The fibrous layer originates from the branchial arch mesenchyme, an embryonic connective tissue derived from the mesoderm, which explains the extensive presence of collagen type II in the pars tensa as a product of TM fibroblasts. MSCs are adult undifferentiated immature cells with fibroblast- like morphology, originating from the mesoderm and capable of self-renewal and pluripotency [39]. Moreover, MSCs have been reported to share a significant number of biologic characteristics with fibroblasts [40]. We thus selected human MSCs from the bone marrow as a suitable cellular model to test the TM scaffolds.

Over the past years, multiscale fiber networks have been proposed with the purpose to empower scaffold architecture by tuning the combination between structural and topographic cues [41]. Moreover, thanks to the contemporaneous presence of microand nano-sized elements, the biologic performance is usually improved. There are several evidences showing that ultrafine fibers promote MSC spreading and viability. Tuzlakoglu et al used a two-step method that exploited fiber bonding and ES, showing that cytoskeletal organization and viability of human MSCs was positively influenced by the electrospun fibers [42]. Pham et al investigated bilayered scaffolds manufactured via ES as alternating layers of micro- and nano-fibers, and reported an enhanced spreading, but reduced $3 \mathrm{D}$ infiltration by rat MSCs [43]. Cellular infiltration has been observed on thick meshes obtained via ES, showing that the cells were able to penetrate up to a $100 \mu \mathrm{m}$ depth on diverse types of electrospun scaffolds [44, 45]. The meshes produced in this study were very thin, suggesting that cell infiltration may occur. However, this phenomenon is influenced by cell size, which can vary from tens-tohundreds microns, depending on both the specific cell type and the animal species. The scaffolds investigated in this study are all based on ES, while AM was used to impart multiscale structuring with biomimetic topography.

Single scale TM scaffolds were produced using customized collector and equipment that had been previously set up and optimized for PLGA. In the first instance, this copolymer was chosen as a model for our study. Indeed, PLGA is widely used to produce electrospun scaffolds for soft TE because of its biocompatibility and tunable degradation properties [46]. The production of patterned electrospun meshes with different fiber alignment can be achieved through diverse methods [22, 47]. In particular, customized collectors have been used to produce spatial fiber alignment. As an example, electrospun radial fibers have been recently proposed by Xie et al [47], while Vaquette and collaborators have tested different collectors to achieve complex fiber harvest with diverse mesh patterning [22]. Our ES method allowed the single-step manufacturing of radial patterned scaffolds at the macroscale level, as a result of mesh thickening along the collector radii. However, this patterning effect was found to disappear with mesh growth, while it was maintained for collection times up to $2 \mathrm{~min}$. Using 2 min collection times, no increase in mesh thickness was detected so that membranes collected after $1 \mathrm{~min}$ were chosen for cellular experiments. The highest 
thickness of the pattern obtained with 1 min collection time was $23.19 \pm 5.97 \mu \mathrm{m}$ on the outer border and $26.22 \pm 12.71 \mu \mathrm{m}$ on the inner rays, thus creating a dip theoretically suitable for containing and guiding cells in a TM replacement. However, the membrane was still very thin $(24.61 \pm 8.15 \mu \mathrm{m})$ and delicate at handling that it barely satisfied the minimal requirements of mechanic stability [13].

The application of 3D printed grids on a thin electrospun membrane represents a smart solution to achieve both the zonal growth of cells and the structural reinforcement of the scaffold. Ideally, the production of TM scaffolds could only be obtained by producing different layers of electrospun fibers resembling the natural ECM of the human TM. However, the tiny thickness of the mesh needed to replace human TM thickness $(<100 \mu \mathrm{m})$ is a limiting factor for TM scaffold production and handling during biological in vitro tests and surgery. This problem was solved by combining AM and ES. The presence of the microfiber AM pattern helps in various ways: (i) it avoids curling of the graft due to the small thickness of the electrospun mesh, (ii) the external contour of the AM microfiber pattern can help fixation to the TM bony annulus, (iii) the central part of the AM microfiber pattern can favor the connection to the remaining ossicular chain or prosthesis, and (iv) it prevents the TM scaffold to break at implantation. Generally, the combination of AM and ES techniques is proposed in literature for the possibility of producing scaffolds with suitable mechanical properties, thanks to the macro- and micro-size 3D structure produced by AM techniques and to the good biological performance in the presence of nano-sized elements [26, 48]. Moreover, the presence of oriented ultrafine fibers has shown to induce different cell morphology $[26,49]$.

Dual and triple scale scaffolds were manufactured via ES combined with $\mathrm{AM}$, using $\mathrm{PEOT/PBT}$ under AM parameters described elsewhere [28]. The choice of this copolymer for dual and triple scale manufactures relied on the fact that PLGA cannot be efficiently processed via AM. Moreover, the use of one material for scaffold assembly was preferred to prevent delamination of its sub-parts. This copolymer is one of the synthetic materials that was tested in middle ear implants and showed positive results. A copolymer of the PEOT/PBT family was first investigated for TM applications by Bakker et al in 1990 [50, 51]. In the following year, salt-casted porous films based on this copolymer were investigated as TM replacements. They were reported to have thickness of $100 \mu \mathrm{m}$, porosity of $50 \%$ and pore size of $160 \mu \mathrm{m}$ [52]. The biocompatibility of these devices was tested in a rat model and observations performed after two and four weeks showed epidermis and epithelium layers covering the implant, with a mild foreign body reaction after implantation. After one year, more than $50 \%$ of the material had degraded. In this article, Grote and colleagues have reported some key features that in their experience concurred to explain the general failure of polymeric TM replacements. Among them, correct scaffolding properties, including pore topography, seemed to play a pivotal role, while inflammatory reactions and early degradation of the substrate were undesirable [52]. At that time TE was at its very onset and biomaterials were broadly considered by clinicians as mere prosthetic replacements. Therefore, owing to a considerable number of failures following the implantation of many synthetic materials in the middle ear, in the second half of the twentieth century otologic surgeons mainly focused on biologic materials (e.g., silk) and auto- or allo-grafts. Some TE studies on TM have been later reported [13-18]. However, specific biomimetic patterning to replace its fibrous structure has never been proposed so far.

In this study, AM fabricated grid layers were used to obtain grooved TM scaffolds. With this technique the height of the patterns was much taller $(352 \pm 32 \mu \mathrm{m})$ than that obtained with direct ES $(26.22 \pm 12.71 \mu \mathrm{m})$, and ensured zonal cell separation in the preformed districts. It has to be noted that the outer thickness-to-diameter ratio varied from $2 / 1000$ of the single scale, to $2 / 100$ of the dual scale and $4 / 100$ of the triple scale TM scaffolds. This discrepancy, especially between the single scale and the dual/triple scale matrices, has often compelled the use of identical measurement methods. PLGA electrospun meshes have been reported to have porosity ranging in $68-92 \%$, depending on several manufacturing parameters [46], while PEOT/PBT meshes to have a porosity of $95 \%$ [28]. Both copolymer meshes obtained via ES showed prevalence of pores belonging to two main size classes, namely $3-10$ and $10-30 \mu \mathrm{m}$. In the PEOT/PBT meshes, the measurement technique used (i.e., MIP) allowed the detection of a broad number of pore size classes, including the $30-100 \mu \mathrm{m}$ class as the largest pore size revealed in these samples. The marked presence of the 3-10 and $10-30 \mu \mathrm{m}$ classes is highly significant: the former sustains the cells offering many anchoring points and provides the exchange of small molecules, while the latter enables the infiltration of cells of appropriate size. Human MSCs are known to be medium-to-large cells, whose size may exceed $100 \mu \mathrm{m}$ [53], thus, in our application, the presence of the $30-100 \mu \mathrm{m}$ pore class had some relevancy for putative cell infiltration. The TM scaffolds showed higher porosity and lower pore size (although distributed across different classes) than those reported by Grote et al [52]. However, the surface area offered by electrospun meshes for cell adhesion was much higher than that offered by the porous film tested in their study. This parameter, together with high porosity and diversified pore dimensions of the described TM replacements is supposed to enhance the cellcopolymer cohesion and enable the neo-tissue formation upon material degradation in vivo. Our biologic results were primarily focused on the assessment of in vitro cytocompatibility using human MSCs, as a 
model of primary human cells for TM regeneration. Specifically, a spatially predefined disposition of cells, preparatory to a biomimetic deposition of ECM after their differentiation, was considered a primary goal of this investigation.

The MSCs on single scale scaffolds were mainly located within the sectors delimited by the radial micro-patterns, penetrated the fiber mesh and expressed f-actin, although several cells could be detected across the ridges. MSCs showed a low viability (on average, $10.5 \%$ ) that was maintained over culture time with no statistically significant changes, while a statistically significant reduction in cell number and proteins per area $\left(1.00 \pm 0.16\right.$ and $1.94 \pm 0.30 \mathrm{ng} \mathrm{mm}^{-2}$, respectively) was observed with respect to the dual and triple scale constructs. The difficulty in handling and preparation, together with putative microdefects as a consequence of thinness and fragility of these scaffolds can cause cell loss at seeding, leading to reduced cellularity of the constructs at the endpoint. Differently, dual and triple scale scaffolds showed the highest cell viability (on average, 23.9 and $18.4 \%$, for dual and triple scale, respectively), cellularity $(4.17 \pm 0.76$ and $4.82 \pm 0.5 \mathrm{ng}$ ds-DNA $\mathrm{mm}^{-2}$, for dual and triple scale, respectively, $p=$ n.s.) and synthesized proteins $\left(3.71 \pm 0.33\right.$ and $4.02 \pm 0.36 \mathrm{ng} \mathrm{mm}^{-2}$, for dual and triple scale, respectively, $p=$ n.s.), with either low statistical power or, more often, no statistically significant differences between dual and triple scale constructs. In particular, in both construct types cell viability had a statistically significant overall increase at the endpoint, cellularity was $4-5$ times and proteins were about 2 times higher than those of single scale constructs. Topographically, dual scale scaffolds, of easier manufacturing than triple scale ones, allowed cell disposal within bi-dimention confined sectorial areas delimited by the grid fibers. The MSCs well adhered to the grid fibers and expressed $\mathrm{f}$-actin, thus resulting in densely colonized constructs by highly stretched cells. A histologic analysis was additionally pursued to verify the infiltration capability of human MSCs inside the PEOT/PBT electrospun meshes, showing that the MSCs were able to penetrate into the mesh thickness, both in dual and triple scale TM scaffold/MSC constructs. Evidence of cell infiltration was corroborated by the presence of pores in the PEOT/PBT meshes with size comparable to that of human MSCs, thus suggesting the possible formation of full thickness biohybrid membranes in vivo.

However, only the double-side patterning (radial and circular), as obtained by triple scale scaffold manufacturing, permitted a really biomimetic cellular disposal. The cells massively settled themselves along one-dimensional directions, retracing the peculiar arrangement of collagen fibers in human TM. The accomplishment of this objective may represent the first step for the production of functional bioconstructs, either in vitro or in vivo, empowered by appropriate side-specific and directionally controlled collagen fibers. This would theoretically enable TM replacements of enhanced efficacy and biocompatibility at the service of patients and otologic surgeons.

\section{Conclusions}

This study demonstrates the possibility to fabricate biomimetic scaffolds for TM replacement via advanced scaffolding approaches, specifically, using customized collector-based ES, and AM combined with ES. The first technique allowed the production of radially patterned scaffolds, while the second technique enabled the manufacturing of dual and triple scale scaffolds with radial and circular biomimetic grooves, either combined in the form of a single grid on one side, or two grids singularly applied on each side of the electrospun membrane. All the scaffolds permitted the adhesion of human MSCs that were viable and penetrated the electrospun fiber mesh, expressing well developed f-actin. In particular, the scaffolds manufactured with triple scale fabrication supported very good cellularity on both surfaces together with the best biomimetic cell disposition, which well retraced the peculiar arrangement of collagen fibers in human TM. These findings pave the way for future biofabrication of autologous TM replacements ex vivo, as an alternative approach for the treatment of large TM perforations based on TE.

\section{Acknowledgments}

The authors declare that there are no conflicts of interest. This study was supported by the Tuscany Region (Health Program 2009) and by the Italian Ministry of University and Research (PRIN 2010S58B38). The Authors wish to thank Dr Gianni Ciofani (IIT, Pontedera, Italy), Cristina Bartoli and Matteo Gazzarri (University of Pisa, Italy) for their technical support with confocal microscopy, Dr Stefania Moscato and Dr Sabrina Danti (University of Pisa, Italy) for their contributions to spectrophotometric and statistical analyses, respectively. Finally, Dr Roberto Pini (CNR, Pisa, Italy) is greatly acknowledged for Mercury Intrusion Porosimetry measurements.

\section{References}

[1] Fay J, Puria S, Decraemer W F and Steele C 2005 Three approaches for estimating the elastic modulus of the tympanic membrane J. Biomech. 38 1807-15

[2] Daphalapurkar N P, Dai C, Gan R Z and Lu H 2009 Characterization of the linearly viscoelastic behavior of human tympanic membrane by nanoindentation J. Mech. Behav. Biomed. Mater. 282-92

[3] Volandri G, Di Puccio F, Forte P and Carmignani C 2011 Biomechanics of the tympanic membrane J. Biomech. 44 1219-36

[4] Monasta L, Ronfani L, Marchetti F, Montico M, Vecchi Brumatti L, Bavcar A, Grasso D, Barbiero C and 
Tamburlini G 2012 Burden of disease caused by otitis media: systematic review and global estimates PLoS One 7 e 36226

[5] Mehta R P, Rosowski J J, Voss S E, O’Neil E and Merchant S N 2006 Determinants of hearing loss in perforations of the tympanic membrane Otol. Neurotol. 27 136-43

[6] Feenstra L, Kohn F E and Feyen J 1984 The concept of an artificial tympanic membrane Clin. Otolaryngol. Allied. Sci. 9 215-20

[7] Deng Z, Wu J, Qiu J, Wang J, Tian Y, Li Y and Jin Y 2009 Comparison of porcine acellular dermis and dura mater as natural scaffolds for bioengineering tympanic membranes Tissue Eng. A 15 3729-39

[8] Rahman A, Olivius P, Dirckx J, Von Unge M and Hultcrantz M 2008 Stem cells and enhanced healing of chronic tympanic membrane perforation Acta Otolaryngol. 128 352-9

[9] Marquet J 1971 Human middle ear transplants J. Laryngol. Otol. 85 523-40

[10] Kerr A G 1980 Homografts in the middle ear J. R. Soc. Med. 73610

[11] Dornhoffer J L 1997 Hearing results with cartilage tympanoplasty Laryngoscope 107 1094-9

[12] Kaftan H 2010 Tympanic membrane reconstruction with nonautogenous transplants and alloplastic materials Laryngorhinootologie 89 562-8

[13] Teh B M, Marano R J, Shen Y, Friedland P L, Dilley R J and Atlas M D 2013 Tissue engineering of the tympanic membrane Tissue Eng. B: Rev. $19116-32$

[14] Hong P, Bance M and Gratzer P F 2013 Repair of tympanic membrane perforation using novel adjuvant therapies: a contemporary review of experimental and tissue engineering studies Int. J. Pediatr. Otorhinolaryngol. 77 3-12

[15] Kanemaru S, Umeda H, Kitani Y, Nakamura T, Hirano S and Ito J 2011 Regenerative treatment for tympanic membrane perforation Otol. Neurotol. 32 1218-23

[16] Kim Jet al 2011 A healing method of tympanic membrane perforations using three-dimensional porous chitosan scaffolds Tissue Eng. A 17 2763-72

[17] Ghassemifar R, Redmond S, Zainuddin and Chirila T V 2010 Advancing towards a tissue-engineered tympanic membrane: silk fibroin as a substratum for growing human eardrum keratinocytes J. Biomater. Appl. 24 591-606

[18] Levin B, Redmond S L, Rajkhowa R, Eikelboom R H, Marano R J and Atlas M D 2010 Preliminary results of the application of a silk fibroin scaffold to otology Otolaryngol. Head Neck Surg. 142 S33-5

[19] Roosli C, von Buren T, Gassmann N B and Huber A M 2011 The impact of platelet-derived growth factor on closure of chronic tympanic membrane perforations: a randomized, double-blind, placebo-controlled study Otol. Neurotol. 32 1224-9

[20] Agarwal S, Wendorff J H and Greiner A 2009 Progress in the field of electrospinning for tissue engineering applications Adv. Mater. 21 3343-51

[21] Martins A, Alves da Silva M L, Faria S, Marques A P, Reis R L and Neves N M 2011 The influence of patterned nanofiber meshes on human mesenchymal stem cell osteogenesis Macromol. Biosci. 11 978-87

[22] Vaquette C and Cooper-White J J 2011 Increasing electrospun scaffold pore size with tailored collectors for improved cell penetration Acta Biomater. 7 2544-57

[23] Townsend-Nicholson A and Jayasinghe S N 2006 Cell electrospinning: a unique biotechnique for encapsulating living organisms for generating active biological microthreads/ scaffolds Biomacromolecules 7 3364-9

[24] Jayasinghe S N 2013 Cell electrospinning: a novel tool for functionalising fibres, scaffolds and membranes with living cells and other advanced materials for regenerative biology and medicine Analyst 138 2215-23

[25] Mota C, Puppi D, Chiellini F and Chiellini E 2012 Additive manufacturing techniques for the production of tissue engineering constructs J. Tissue Eng. Regen. Med. 9174-90

[26] Mota C, Puppi D, Dinucci D, Errico C, Bartolo P and Chiellini F 2011 Dual-scale polymeric constructs as scaffolds for tissue engineering Materials 4 527-42
[27] Puppi D, Piras A M, Detta N, Dinucci D and Chiellini F 2010 Poly(lactic-co-glycolic acid) electrospun fibrous meshes for the controlled release of retinoic acid Acta Biomater. 6 1258-68

[28] Moroni L, Schotel R, Hamann D, de Wijn J R and van Blitterswijk C A 2008 3D fiber-deposited electrospun integrated scaffolds enhance cartilage tissue formation $A d v$. Funct. Mater. 18 53-60

[29] Puppi D, Detta N, Piras A M, Chiellini F, Clarke D A, Reilly G C and Chiellini E 2010 Development of electrospun three-arm star poly(epsilon-caprolactone) meshes for tissue engineering applications Macromol. Biosci. 10 887-97

[30] Landers R, Pfister A, Hubner U, John H, Schmelzeisen R and Mulhaupt R 2002 Fabrication of soft tissue engineering scaffolds by means of rapid prototyping techniques J. Mater. Sci. 37 3107-16

[31] Lim D J 1995 Structure and function of the tympanic membrane: a review Acta Otorhinolaryngol. Belg. 49 101-15

[32] Woodfield T B, Miot S, Martin I, van Blitterswijk C A and Riesle J 2006 The regulation of expanded human nasal chondrocyte re-differentiation capacity by substrate composition and gas plasma surface modification Biomaterials 27 1043-53

[33] Trombi L, Mattii L, Pacini S, D'Alessandro D, Battolla B, Orciuolo E, Buda G, Fazzi R, Galimberti S and Petrini M 2008 Human autologous plasma-derived clot as a biological scaffold for mesenchymal stem cells in treatment of orthopedic healing J. Orthop. Res. $26176-83$

[34] Singer V L, Jones L J, Yue S T and Haugland R P 1997 Characterization of PicoGreen reagent and development of a fluorescence-based solution assay for double-stranded DNA quantitation Anal. Biochem. 249 228-38

[35] Dormer KJ and Gan R Z 2001 Biomaterials for implantable middle ear hearing devices Otolaryngol. Clin. North Am. 34 289-97

[36] Danti S, D'Alessandro D, Pietrabissa A, Petrini M and Berrettini S 2010 Development of tissue-engineered substitutes of the ear ossicles: PORP-shaped poly(propylene fumarate)-based scaffolds cultured with human mesenchymal stromal cells J. Biomed. Mater. Res. A 92A 1343-56

[37] Ingber D E, Mow V C, Butler D, Niklason L, Huard J, Mao J, Yannas I, Kaplan D and Vunjak-Novakovic G 2006 Tissue engineering and developmental biology: going biomimetic Tissue Eng. 12 3265-83

[38] Mallo M 1998 Embryological and genetic aspects of middle ear development Int. J. Dev. Biol. 42 11-22 (www.ijdb.ehu.es/web/ paper.php?doi=9496782)

[39] Bianco P, Robey P G and Simmons P J 2008 Mesenchymal stem cells: revisiting history, concepts, and assays Cell Stem Cell 2313-9

[40] Hematti P 2012 Mesenchymal stromal cells and fibroblasts: a case of mistaken identity? Cytotherapy 14 516-21

[41] Kim G, Son J, Park S and Kim W 2008 Hybrid process for fabricating 3D hierarchical scaffolds combining rapid prototyping and electrospinning Macromol. Rapid Commun. 29 1577-81

[42] Tuzlakoglu K, Bolgen N, Salgado A J, Gomes M E, Piskin E and Reis R L 2005 Nano- and micro-fiber combined scaffolds: a new architecture for bone tissue engineering J. Mater. Sci. Mater. Med. 16 1099-104

[43] Pham Q P, Sharma U and Mikos A G 2006 Electrospun poly ( $\varepsilon$ caprolactone) microfiber and multilayer nanofiber/microfiber scaffolds: characterization of scaffolds and measurement of cellular infiltration Biomacromolecules 7 2796-805

[44] Leong M F, Chan W Y, Chian K S, Rasheed M Z and Anderson J M 2010 Fabrication and in vitro and in vivo cell infiltration study of a bilayered cryogenic electrospun poly(D, L-lactide) scaffold J. Biomed. Mater. Res. A 94 1141-9

[45] Zhang Y, Ouyang H, Lim C T, Ramakrishna S and Huang Z M 2005 Electrospinning of gelatin fibers and gelatin/PCL composite fibrous scaffolds J. Biomed. Mater. Res. B: Appl. Biomater. 72 156-65

[46] Zhu X, Cui W, Li X and Jin Y 2008 Electrospun fibrous mats with high porosity as potential scaffolds for skin tissue engineering Biomacromolecules 9 1795-801 
[47] Xie J, MacEwan M R, Ray W Z, Liu W, Siewe D Y and Xia Y 2010 Radially aligned, electrospun nanofibers as dural substitutes for wound closure and tissue regeneration applications ACS Nano 4 5027-36

[48] Park S H, Kim T G, Kim H C, Yang D Y and Park T G 2008 Development of dual scale scaffolds via direct polymer melt deposition and electrospinning for applications in tissue regeneration Acta Biomater. 4 1198-207

[49] Nain A S, Phillippi J A, Sitti M, Mackrell J, Campbell P G and Amon C 2008 Control of cell behavior by aligned micro/ nanofibrous biomaterial scaffolds fabricated by spinneret-based tunable engineered parameters (STEP) technique Small 4 1153-9

[50] Bakker D, van Blitterswijk C A, Hesseling S C, Koerten H K, Kuijpers W and Grote J J 1990 Biocompatibility of a polyether urethane, polypropylene oxide, and a polyether polyester copolymer. A qualitative and quantitative study of three alloplastic tympanic membrane materials in the rat middle ear J. Biomed. Mater. Res. 24 489-515

[51] Bakker D, van Blitterswijk C A, Hesseling S C, Th Daems W, Kuijpers W and Grote J J 1990 The behavior of alloplastic tympanic membranes in Staphylococcus aureus-induced middle ear infection: I. Quantitative biocompatibility evaluation J. Biomed. Mater. Res. 24 669-88

[52] Grote J J, Bakker D, Hesseling S C and van Blitterswijk C A 1991 New alloplastic tympanic membrane material Am. J. Otol. 12 329-35 (PMID: 1665011)

[53] Danti S, D'Acunto M, Trombi L, Berrettini S and Pietrabissa A 2007 A micro/nanoscale surface mechanical study on morpho-functional changes in multilineage-differentiated human mesenchymal stem cells Macromol. Biosci. 7 589-98 